\title{
Cultural Influences Moderating Learners' Adoption of Serious 3D Games for Managerial Learning
}

\author{
Haytham Siala* \\ Newcastle University Business School \\ London \\ United Kingdom \\ haytham.siala@newcastle.ac.uk \\ Elmar Kutsch \\ Cranfield School of Management \\ Bedfordshire \\ United Kingdom \\ e.kutsch@cranfield.ac.uk \\ Suzy Jagger \\ University of Roehampton Business School \\ London \\ United Kingdom \\ s.jagger@roehampton.ac.uk
}

Funding: The software development was part of a matched funding project between the University of Roehampton, and a European NGO, ORT France.

* Corresponding author 


\begin{abstract}
Purpose - This paper investigates whether learners from different cultures adopt a serious 3D game to facilitate the learning of transferable managerial skills (ethics) and knowledge.

Design/methodology/approach - A cross-sectional, cross-country survey study ( $n=319)$ was conducted recruiting participants from one North-American and two British universities. The survey data and the conceptual model has been analysed and tested using CFA (confirmatory factor analysis) and SEM (structural equation modelling).
\end{abstract}

Findings - Participants displayed positive attitudes towards the 3D game and responded positively to theory presented as 'real life' scenarios; gamification techniques such as interactions and dialogue, and rewards and progression levels, which are part of the game, albeit the participants' adoption was driven more by extrinsic motivations (rewards) than intrinsic ones (ease-of-use and entertainment). In addition, the empirical results suggest that when gender is taken into account, the perceptions and needs of cross-cultural learners in serious gaming environments vary and display characteristics that are similar to Rogers' five adopter categories; thus, culture could significantly shape learners' decisions to adopt a serious game as a managerial learning tool. Research limitations/implications - For future researchers, this paper highlights various levels of training, support and promotional awareness that need to be considered to facilitate the adoption of serious games for managerial learning.

Practical/implications - For academics and practitioners in work-based learning and managerial training environments, this paper highlights the salient factors that need to be inherent in a serious 3D game, and best practices for scaffolding existing instructional approaches or training interventions.

Originality/value -In light of Rogers' five adopter categories, this cross-country study involving culturally diverse learners provides key insight into the potential application of serious games as a practice-based learning instrument in academia and industry. 
Keywords - serious games; technology-mediated andragogy; adoption theory, practice-based learning

Paper type Research paper

\section{INTRODUCTION}

The literature in management education is inundated with articles criticising traditional instructional methods for being bland, disengaging, and not equipping learners with the professional transferable skills and knowledge needed in the workplace (Pfeffer and Fong, 2004, Daspit and D'Souza, 2012, Ashkanasy, 2006, Armstrong, 2011, Egri, 2013, Salas, Wildman and Piccolo, 2009). In addition, graduates of business management degrees who are not exposed to practice-based and experiential learning environments could find applying what they have learned in a corporate environment, challenging (Salas, Wildman and Piccolo, 2009, Mustar, 2009). The transformative role of information technology in delivering business management courses has been covered quite extensively in the literature of management education (Daspit and D'Souza, 2012, Geddes, 2009, Mustar, 2009, Whitaker,New and Ireland, 2016, Alavi,Yoo and Vogel, 1997, Lee and Choi, 2011, Lee,Choi and Kim, 2013, Arbaugh,DeArmond and Rau, 2013, Phan,Siegel and Wright, 2009) with research themes revolving around topical issues such as blended and technology enhanced learning (Whitaker,New and Ireland, 2016, Alavi,Yoo and Vogel, 1997, Neville,Heavin and Walsh, 2005, Kawalek and Hart, 2007), and computer-based simulation games (Pasin and Giroux, 2011, Salas,Wildman and Piccolo, 2009, Viswanath Venkatesh and Bala, 2008, Visawanath Venkatesh and Speier, 2000, Siemer and Angelides, 1997). Serious games, which represent the constructivist approach to learning or 'learn by doing' (David Kolb, 1984) are computer-based simulation games but unlike traditional computer-based educational games where the main focus is on enhancing engagement and edutainment, serious games are used in professional practice and corporate training interventions to help learners and trainees 
acquire and develop practical, transferable skills and knowledge (Newbery,Lean and Moizer, 2016, Bridget and Andrea, 2011, Salas, Wildman and Piccolo, 2009, Newbery et al., 2018). The virtues of serious simulation games include: imparting theory and practice by providing learners with an authentic learning experience; a risk-free learning environment for where learners evaluate and experience real-life situations without worrying about consequences of any actions or decisions they make (Salas, Wildman and Piccolo, 2009, Hainey et al., 2011, Murnane and Browne, 2016, Allal-Chérif and Makhlouf, 2016, Newbery et al., 2018). Some critics of serious games highlighted the andragogical barriers to serious games adoption. For example, it has been argued that learning tasks in serious games do not align with the learning outcomes or curriculum of the taught course that they are supposed to complement (Leemkuil and De Jong, 2012, Wu et al., 2012); however, studies that examined the potential cultural barriers to adoption of educational technologies including serious games are a paucity in the literature(Al-Senaidi,Lin and Poirot, 2009).

To sum up, although a few articles are touting the andragogical effectiveness of serious games; there is little evidence in the multidisciplinary literature on cultural barriers to adoption of serious games as a learning tool; thus, this study explores the adoption of a serious 3D ethics as a practice-based managerial learning tool.

The remainder of this article is structured as follows: the next section will review literature on the issues and challenges facing traditional teaching methods in business management education. Adoption theory will be discussed in subsequent sections, followed by a discussion of the conceptual model, hypotheses, research method, empirical settings, recruitment method of participants, and data collection instruments. The article will then discuss the andragogical and practical implications in light of the findings of this research study, and it will conclude with a section outlining this study's limitations and opportunities for further research. 


\section{LITERATURE REVIEW}

Researchers have addressed the call for innovative and practice-based teaching methods by proposing alternative instructional approaches (Mustar, 2009, Michaelson, 2016, Moshavi, 2001, Verzat,Byrne and Fayolle, 2009, Waller,Lei and Pratten, 2014). Mustar (2009) suggests adopting a 'hybrid' instructional approach that encompasses traditional and practice-based teaching methods such as business simulations, interviews with practitioners, and assignments designed by practitioners from the industry. Waller et al. (2014) proposed using a simulated "crisis management" scenario (such a product recall crisis) to engage students and to help them develop reflective, communication, teamwork, and problem-solving skills. Moshavi (2001) suggested delivering in-class exercises through improvisational theatre techniques such as role-playing to stimulate creativity, engagement in class discussions, group formation and to enhance learners' confidence in handling risky decisions while Michaelson (2016) suggested the use of novels as alternative andragogy to teach business ethics. Prior research advocates Michaelson's 'novels' instructional approach as findings suggest that the immersive physiological experience of transporting into a fictitious world that is triggered by reading a novel emulates the experience of interacting socially and emphatically with people in the real world (Mar, 2011). To stimulate the immersive physiological experience of learners, the serious 3D game used in this research study uses an immersive 3D environment based on a novel-type storyline where interactive characters appear in three different familiar environments. The storyline in the game involves a main character who plays the role of a marketing manager in a competitive marketing firm facing different ethical scenarios.

\section{Experiential Learning in Serious Gaming Environments}

The aim of game-based learning is to engage students and enhance their learning experience by introducing an entertainment element to the learning tasks (Jagger,Siala and Sloan, 2015, Sung and Hwang, 2013). Findings from prior research found that game-based 
learning stimulates deeper and more practical learning (Bloom, 2009, Mustar, 2009), which eventually improves learners' critical thinking and problem-solving skills (Kapp, 2012, Ke, 2008a) and makes a taught subject more interesting (Bloom, 2009, Tobias,Fletcher and Wind, 2014).

\section{Serious Games}

Serious simulation games represent the constructivist approach of 'learn by doing' (David Kolb, 1984) and they are intended more for education rather than entertainment as they are designed to prime individuals with the skills and knowledge needed in the corporate world (Papastergiou, 2009, Newbery,Lean and Moizer, 2016, Bridget and Andrea, 2011). Prior studies have commended serious games as effective alternative teaching methods to traditional instructional approaches (Pasin and Giroux, 2011, Wolfe, 1997, Salas,Wildman and Piccolo, 2009) by accentuating the distinctive advantages that are associated with serious games such as an authentic, self-regulated and risk-free learning experience that is reinforced by simulated and interactive real-life business scenarios (Hainey et al., 2011, Murnane and Browne, 2016, Salas, Wildman and Piccolo, 2009, Lean,Moizer and Newbery, 2014) and the provision of prompt feedback to learners (Bartunek, 2014). Some researchers assert that the hands-on learning process and skills development is enhanced when a serious game uses an immersive 3D environment that accurately models the organisation of interest (Liu,Cheng and Huang, 2011, Yang, 2012, Kebritchi,Hirumi and Bai, 2010, Pasin and Giroux, 2011) and when the learning tasks are perceived to be intellectually stimulating (Liu,Cheng and Huang, 2011). The prospects of tapping into serious games as an alternative or adjunct teaching method coincide with the growing technological and gaming skills of prospective millennial and Generation Z students (Nielsen, 2009, Pratchett, 2005, Afari et al., 2013, Whitton, 2012). The potential of serious games as an alternative learning and training method is advocated further by the inception of different academic and research consortia such as the Serious 
Games Institute in Coventry University (UK) whose specific remit is to address the hurdles to serious game adoption in educational and corporate environments.

\section{Adoption Theory}

The development of emerging serious 3D gaming environments has provided many opportunities for education suppliers to explore and develop new ways of delivering educational programs. Adoption theory refers to the choice an individual makes to either accept or reject a new and unfamiliar product or service (Foxall and Bhate, 1993, Walden and Browne, 2009, Straub, 2009). According to adoption theory, there are multiple factors responsible for shaping the decision of an individual or organisation including extent of knowledge and awareness about the product, social norm and peer pressure, tendency to accept an innovation, perceived advantages, compatibility and complexity of an innovation, observability or tangible outcomes from applying an innovation, and trialability or opportunity to thoroughly test an innovation before actual commitment (Frambach and Schillewaert, 2002).

Overall, the adoption of innovative products gains momentum with time by gradually progressing through five adopter stages: innovators, early adopters, early majority, late majority and laggards (Rogers, 2010):

1. Innovators - These are venturesome risk-taking enthusiasts who are interested in testing avant-garde ideas and innovations and thus, need little or no promotional awareness and persuasion to adopt an innovation.

2. Early Adopters - These are opinion leaders who are open to change and innovations and thus, they would feel comfortable with adopting new ideas. Like the Innovators, they need little or no promotional awareness and persuasion to convince them to adopt an innovation; however, basic support and materials such as user guides and how-to operating manuals would suffice to support this adopting group. 
3. Early Majority - This adopting group is less likely to comprise opinion or thought leaders, but they are prone to adopting new ideas and innovations before an average person does. They would contemplate adopting an innovation after gathering reassuring evidence about the effectiveness of the innovation in accomplishing its objectives and thus, case studies, success stories demonstrating the innovation's effectiveness could significantly inform this adopting group's decisions.

4. Late Majority - These are risk-averse skeptics who are reluctant to change. They usually adopt a cautious 'wait and see' approach where they patiently wait for the majority to try and verify the effectiveness of an innovation; thus, information and stats about people who successfully tried and adopted an innovation could inform this adopting group's decision.

5. Laggards - These are conservatives strictly bound by tradition and social norms. They are very risk-averse and skeptical of change and convincing them to adopt an innovation would be a monumental challenge. Like the Late Majority group, reassuring stats about people who adopted this innovation successfully and peer pressure from other adopting groups could attenuate their concerns about adopting an innovation.

Adoption theory has been applied in a range of contexts including education (Renda dos Santos and Okazaki, 2016). Organisations can potentially benefit from research studies that apply adoption theory to form a better understanding of the relationship between individual and organisational reactions towards a new product or service and their likelihood of adopting that product or service, which subsequently can help them in deriving different promotional strategies for targeting adopters to expedite the adoption process (Frambach and Schillewaert, 2002, Chaffey and Ellis-Chadwick, 2016). This paper investigates from an adoption theory perspective learners' perceptions and attitudes towards adopting serious 3D 
games as a practice-based managerial learning tool based on a prominent discrete theory: The Technology Acceptance Model (TAM).

The main premise of TAM, which is based on the Theory of Reasoned Action (TRA) and Theory of Planned Behaviour (TPB) (I. Ajzen, 2002, Icek Ajzen, 1988) is that users are more likely to adopt a system if they perceive a system to be useful in accomplishing a task (perceived usability) without a steep learning curve (perceived ease of use) (Davis, 1993, Davis,Bagozzi and Warshaw, 1989). Findings from prior research that contextualised TAM in e-learning and corporate training environments suggest that extrinsic motivations can affect users perception of a system's perceived usability while perceived ease of use can be affected by users' intrinsic motivations (Raafat Saadé and Bahli, 2005, V. Venkatesh,Speier and Morris, 2002, Viswanath Venkatesh, 1999). Since this study is focusing on evaluating the andragogical effectiveness of a technology rather than user acceptance of a technology, this research study has used an adapted version of TAM (Jagger,Siala and Sloan, 2015, Yusoff,Crowder and Gilbert, 2010) to assess whether learners perceive a serious 3D gaming environment to be effective for the learning of practical ethical decision-making skills and knowledge. There are three antecedents in the conceptual model that predict the effectiveness of situated learning (SL), which is a self-reported measure of learning experience: reward (R), perceived ease-of-use (EOU), and perceived effectiveness (PE) of a serious game as a practice-based managerial learning tool.

\section{Relationship between Culture and Andragogy}

Prior research in cross-cultural education indicates that culture impacts significantly on an individual's acceptance of a learning instrument or method (Yamazaki, 2005, Joy and Kolb, 2009, Al-Senaidi,Lin and Poirot, 2009). For example, learners from high power distance cultures engage less in active classroom debates and continuously consult instructors for guidance, but in contrast, learners in low power distance cultures are autonomous and self- 
motivated in seeking out information and knowledge (Joy and Kolb, 2009, G. Hofstede, 2010). Auyeung and Sands (1996) demonstrated in an empirical study that in individualistic cultures, dealing with new and uncertain situations and being innovative and adaptive is the norm whereas, in collectivist cultures, adaptation and innovation are regarded as a challenge. To the authors' knowledge, there is no evidence in the literature of studies that examined Hofstede's other cultural dimensions such as masculinity-femininity, in the context of management education.

To sum up, previous studies on technology adoption in education have paid little attention to the cultural background of a learner. As a consequence, this study sheds light on the cultural context of learners in higher education and its potential impact on the decision to adopt technologies that are conducive to managerial learning.

\section{THEORETICAL FRAMEWORK}

This research study aims to answer a topical research question: What influence does culture have on a learner's decision to adopt a serious game as a learning instrument? This research question is based on the premise that the adoption of a learning instrument including technology-mediated andragogy can be influenced by a learner's cultural background and his or her perception of whether serious games are effective conduits for managerial learning.

The next section will draw on the key concepts and findings from the literature that discourse the cognitive, technological and cultural challenges on learners' perception and response to a teaching method and subsequently, these key findings and concepts will then be used to propose hypotheses that pertain to the potential impact of cognitive, technological and cultural factors on learners' perception and response to serious games as a learning tool. Figure 1 illustrates the conceptual model of this research study.

[Insert Figure 1] 


\section{Hypotheses}

Prior research suggests that an easy-to-use system will help learners focus more on the learning tasks rather than learning how to use the system (Shen and Chu, 2014, Tsung-Li Wang and Tseng, 2014) and additionally, perceived ease of use is postulated to impact significantly on users' decision to adopt a new system as it can shape users' attitudes and intentions to adopt a system on the long-term (Raafat Saadé and Bahli, 2005, V.

Venkatesh,Speier and Morris, 2002, Viswanath Venkatesh, 1999, Roca and Gagné, 2008, Visawanath Venkatesh and Speier, 2000). In general, the prolonged use of a system according to adoption and diffusion theory is a salient indicator of the successful diffusion and adoption of an innovation (Bhattacherjee, 1998); thus, we formulate the following hypothesis:

$\mathrm{H}_{1}$ : There will be a positive relationship between perceived ease of use and the perceived effectiveness of managerial learning through serious game.

Extrinsic and intrinsic motivations can augment the learning experience and motivations of learners (Dean and Beggs, 2006); however, the transfer and assimilation of knowledge and development of transferable skills could be expedited by extrinsic motivations such as a reward or incentivisation scheme (Hwang et al., 2008, Shafer and Simmons, 2011, Smith,Simpson and Huang, 2007, Jagger,Siala and Sloan, 2015). Collectively, these findings suggest the following hypothesis:

$\mathrm{H}_{2}$ : There will be a positive relationship between a rewarding scheme and perceived effectiveness of managerial learning through serious game.

\section{Gender and Culture as Moderators}

Findings from prior empirical studies suggests that female learners engage less with serious games than their male counterparts (Towler,Lean and Moizer, 2009, Newbery,Lean and Moizer, 2016) and that female learners place more emphasis on ease of use when they contemplate adopting an innovative technology whereas technology adoption in male learners 
is determined more by hedonic motivations and social influence (Borrero et al., 2014).

Additionally, prior findings also suggest that females in contrast to males hold lower positive attitudes towards innovative technologies including e-learning and they are more likely to be late adopters or laggards whereas males are more likely to be innovators or early adopters of an innovative technology (Chau and Lung Hui, 1998, Keller and Cernerud, 2002, Laukkanen and Pasanen, 2008, Liaw, 2002, Elliott and Hall, 2005, Borrero et al., 2014, Rosenbaum and Wong, 2015); thus, we formulate the following hypotheses:

$\mathrm{H}_{3}$ : gender will moderate the positive relationship between perceived ease of use and perceived effectiveness of managerial learning through serious game, where the relationship will be stronger from male learners.

$\mathrm{H}_{4}$ : gender will moderate the positive relationship between reward and perceived effectiveness of managerial learning through serious game, where the relationship will be stronger from female learners.

Also, prior research findings in the cross-cultural management education literature suggest that culture plays an instrumental role in the shaping of a learner's cognition, information processing and reaction to a teaching method (Joy and Kolb, 2009, Yamazaki, 2005). High risk-taking behaviour, and being adaptive and innovative was found to be a common trait in individualistic cultures, whereas collectivist cultures were found to be risk-averse and regard adaptation and innovation to be a challenge (Auyeung and Sands, 1996, G. Hofstede, 2010). One can contend that learners from individualistic cultures would come under the innovator or early adopter category since their cultural characteristics (such as risk-taking and open to innovation) suggest that they could adopt serious games early on whereas learners from collectivist cultures will come under the late majority or laggards category; thus, we posit the following hypothesis: 
$\mathrm{H}_{5}$ : individualism will moderate the positive relationship between perceived ease of use and perceived effectiveness of managerial learning through serious game, where the relationship will be stronger from learners affiliating to individualistic cultures.

Prior research has demonstrated that members of high uncertainty avoidance and high power distance cultures are reluctant to change and in problem-solving situations they feel apprehensive about failure and risky decisions; thus, they would adopt a risk-averse or 'waitand-see' decision-making approach to contain uncertainty and ambiguity (House et al., 2004, G. Hofstede, 2010). They prefer conventional learning methods and structured learning situations that involve a single answer and strict timetables (House et al., 2004, Geert Hofstede, 2003) and they would avoid innovative learning methods and experimentation (Joy and Kolb, 2009). Furthermore, they perceive teachers as gurus who can answer everything and thus, depend heavily on instructor guidance to accomplish their learning objectives (House et al., 2004, Geert Hofstede, 2003). In contrast, individuals from low uncertainty cultures and low power distance cultures are adaptive; prefer a flexible structure and deadline and welcome innovative learning methods and ideas (G. Hofstede, 2010); they are not intimidated by uncertainty or risk and prefer learning through experimentation (Joy and Kolb, 2009). Learners from low uncertainty cultures and low power distance cultures are encouraged to be autonomous critical thinkers who can question instructors, challenge extant theories, and conduct new experiments. Thus, one can contend that learners from low uncertainty cultures and low power distance cultures would come under the innovator or early adopter category since their cultural characteristics (such as risk-taking, autonomy, experimentation and open to innovation) suggest that they could adopt serious games early on whereas learners from low uncertainty cultures and low power distance cultures will come under the late majority or laggard category. Collectively, these findings and arguments suggest the following hypotheses: 
$\mathrm{H}_{6}$ : uncertainty avoidance will moderate the positive relationship between perceived ease of use and perceived effectiveness of managerial learning through serious game, where the relationship will be stronger from learners affiliating to low uncertainty avoidance cultures.

$\mathrm{H}_{7}$ : power distance will moderate the positive relationship between perceived ease of use and perceived effectiveness of managerial learning through serious game, where the relationship will be stronger from learners affiliating to low power distance cultures.

\section{RESEARCH METHOD}

The primary aim of this research study is to test hypotheses derived from prior theory; thus, a deductive approach to research was adopted to conduct this research study (Bryman and Bell, 2015). An online cross-sectional survey questionnaire was designed to collect primary data from a cross-country study to examine the relationship between the exogenous and endogenous latent constructs used in this study's research model.

\section{Empirical Settings}

In the light of the past economic crisis and future uncertainties, which were mainly caused or exacerbated by poor ethical decisions, business schools had revised their curriculum to ensure that students graduate with a comprehensive and more in-depth understanding of corporate and social responsibility and business ethics (Adler, 2011). Ethics, morality and sustainability is a salient topic in management education and accreditation bodies such as AMBA and AACSB emphasise the importance of embedding ethics in the business school curriculum (Baden and Higgs, 2015, Michaelson, 2016, Hardy and Tolhurst, 2014). The primary challenge that business management educators are facing is to find an effective instructional approach that engages and equips students with core managerial skills and knowledge including business ethics. 
The empirical settings in this study is a serious 3D ethics game, which incorporates rules and values-based approaches in a simulated real-life environment to foster engagement and meet learning outcomes. The rationale behind using a serious $3 \mathrm{D}$ ethics game in this study is to test its andragogical effectiveness in teaching practical ethical decision-making skills and knowledge. The learning tasks were based on didactic lectures and case studies about contemporary ethical issues, which were used in traditional classroom teaching of ethics. The settings and design of the game include a 3D immersive environment, comic book pages, real-life ethical scenarios, and interactive characters to mimic 'virtual presence' - an emotional 'state' whereby a user is fully immersed in the virtual reality. Collectively, these type of visual settings as immersive 3D environments were found to contextualise users' experiences and elicit emotions, cognitions and behaviours that are akin to those experienced in the real world, which ultimately results in improving learners' perception of the learning instrument or environment, enhancing learners' engagement and potentially, facilitating the acquisition of transferable managerial skills (Papagiannidis et al., 2017, Zhou,Jin and Fang, 2014, Papastergiou, 2009, Kebritchi,Hirumi and Bai, 2010, Agarwal and Karahanna, 2000, Finneran and Zhang, 2005, Novak,Hoffman and Yung, 2000, Schrader and Bastiaens, 2012). The storyline of this 3D ethics game includes a main character, a fictitious marketing manager employed in a competitive marketing company. The student plays the main character who is set to face various ethical dilemmas in familiar 3D environments: an office, a park, and a party. The ethical scenarios are supported by comic book pages and clues to deliver the story narrative. Students receive prompt feedback on the decisions they make and they discover in the final level the consequences of their main decisions; however, to produce a more effective learning experience, the game enables students to retract an inappropriate decision by replaying the same game level, a feature that is consistent with vicarious learning or learning from past failures (Heimbeck et al., 2003, Gino and Staats, 2015, Bledow et al., 
2017, Cajiao and Burke, 2016). The engagement element in the game is addressed through the use of gamification (Klopfer,Osterweil and Salen, 2009) in the form of point accumulation, autonomous play, and progression levels that could lead to a place on the top ten leader board. Figure 2 illustrates an example of an ethical dilemma and the interactions that occur between the player and another character.

\section{[Insert Figure 2]}

Final year undergraduate students $(N=400)$ from one North American and two British universities who were registered on a core Business Ethics module were invited to participate in playing and evaluating the serious $3 \mathrm{D}$ ethics game used in this study. The teaching method, andragogical content, and assessments of the Business Ethics module taught across the three institutions were similar. The instructor briefed the participants about the objectives of the research study and after signing an informed consent sheet, the participants were assured that their responses would remain confidential and anonymous. A $£ 10$ Amazon voucher was offered to participants to complete an online survey questionnaire as a token of appreciation rather than an incentivisation scheme. This sampling strategy which alludes to convenience sampling has been criticised by some researchers for limiting the generalisability of the results. However, the nature of the investigation (game-based learning in academia) and the target population (students) justifies the choice of this sampling strategy and additionally, some researchers argue that convenience sampling is suitable for exploratory studies with an emphasis on generating insights or exploring new ideas (Tuncalp, 1988, Churchill and Iacobucci, 2005).

The number of students who completed the survey was 375 (response rate $=94 \%$ ). Table 1 presents the demographic information of the respondents. The 'ethnic majorities' of the sample are White (41.7\%) and Asian (41.7\%). The proportion of males and females in this sample is $38.6 \%$ and $46.1 \%$, respectively, albeit $15.4 \%$ of respondents have not specified 
their gender. Most of the respondents (61.1\%) have no work experience, and only $26 \%$ of the participants worked for more than two years. The gaming experience of participants varied between avid players (26\% play online games frequently), occasional players $(26.3 \%)$, and $47.7 \%$ have never or seldom play online games.

[Insert Table 1]

\section{Measurement constructs}

To ensure construct validity, the scale items representing the latent constructs were drawn from established validated scales used in previous studies (see Appendix 1). The online survey questionnaire comprises Likert-type scale measurement items where respondents indicate their extent of agreement or disagreement with a statement ( $1=$ "strongly disagree" to $5=$ "strongly agree") and it also includes demographic variables such as age, gender, ethnicity, country of permanent residence, and categorical questions about gaming experience and work experience. The country that participants regard as their home (permanent residence) was used to assign participants to the cultural group dimensions defined in various cross-cultural studies (G. Hofstede, 2010, Yamazaki, 2005, Joy and Kolb, 2009, House et al., 2004). The approach of using home country as a proxy for culture has been questioned by some researchers (Geert Hofstede and McCrae, 2004); however, there are several studies in the cross-cultural management and education literature that have adopted this approach (Joy and Kolb, 2009, Yamazaki, 2005). The high and low categories for each cultural dimension were derived from the sample using the median split method (Iacobucci et al., 2015) and the result for each category is displayed in Table 1. Table 2 displays Hofstede national culture index scores of the participants' countries of origin.

[Insert Table 2]

To confirm that there is a distinct categorisation between the high and low categories in each cultural group, the discriminant index $D$, which is represented by the item-to-total correlation 
test (Theresa JB Kline, 2005) has been calculated after grouping the participants into upper and lower groups based on their national scores on each cultural dimension. A third $(27 \%)$ of the top-ranking and bottom-ranking participants were then selected from the upper and lower groups (Theresa JB Kline, 2005, Ebel and Frisbie, 1991) as 27\% is argued to be the critical ratio that separates the tail from the mean of the standard normal distribution of response error (Theresa JB Kline, 2005). The item-to-total correlation test shows the relationship between the scores of individuals (from the upper and lower groups) on each measurement item representing a construct and the corrected total score of each construct in question; the corrected total score excludes the response to the item in question. The higher the discrimination index $(D)$, the better the item can determine the difference between those with high test scores and those with low ones. The table in Appendix 3 shows that the discriminant index in the upper and lower groups for each cultural dimension is higher than the recommended threshold of 0.5 (Theresa JB Kline, 2005, Ebel and Frisbie, 1991); thus, the upper and lower cultural group categories display distinct categorisation on the individualism, uncertainty avoidance and power distance dimensions.

A pilot study was conducted on a small number of students to examine the psychometric properties and content validity of the questionnaire (Hardesty and Bearden, 2004) and the feedback resulted in slightly changing the wording of a few items. To address common method bias (CMB), Podsakoff's (2003) recommendations were implemented such as performing Harman's one-factor test, displaying questionnaire items in a random order and using negatively worded questions for some items. The Harman single factor test revealed that the single factor solution accounts for approximately $41 \%$ of the variance; thus, common method variance does not seem to be an issue in this study's data set (Podsakoff et al., 2003). A preliminary analysis was conducted as part of a data cleaning process to identify missing cases and outliers. Fifty-one participants who have not responded to some of the key 
questions representing the measurement constructs were later discarded and treated as missing cases (Tabachnick and Fidell, 2007). The Mahalanobis distance for multivariate outliers (Byrne, 2016) was used to identify outliers and the results of the test have revealed that there were five observations that deviated significantly from the centroid and were therefore deleted from the data set. The final sample size in this research study consisted of 319 valid responses after outliers and missing cases were identified and discarded by the researchers.

\section{Structural Equation Modelling (SEM)}

The two-step approach by Anderson and Gerbing (1992) was adopted using the Maximum likelihood method to estimate the measurement and structural model. The size of the sample $(N=319)$ in this research study is adequate for conducting a CFA (confirmatory factor analysis) and SEM test (Malhotra, 2010, Rex B Kline, 2015). The measurement model was tested with a confirmatory factor analysis (CFA) for multi-group invariance using gender groups (Byrne, 2016). The structural model was cross-validated by splitting the sample into two groups, a calibration and a validation group using the random split-half sampling method (Byrne, 2016, Cudeck and Browne, 1983). The aim of the multi-group invariance and crossvalidation test is to ascertain whether the measurement and structural models would replicate consistently across different groups and populations (Byrne, 2016).

\section{Measurement model}

The CFA test revealed that all of the measurement items displayed significant factor loadings (see Table 3) above the recommended threshold of 0.5 (Hair et al., 2010).

[Insert Table 3]

Tests for multivariate normality and multicollinearity (Byrne, 2016) were then conducted on the measurement model. The VIF value for the exogenous constructs was 1.84 and since it is below 5, multicollinearity does not seem to be an issue in this study's data set (O'Brien, 2007); 
however, a test for Mardia's normalized estimate of multivariate kurtosis revealed that multivariate non-normality was an issue (Bentler and $\mathrm{Wu}, 2005$ ). To address the issue of multivariate normality, (i) a Bollen-Stine bootstrapping procedure $(n=2000)$ (Bollen and Stine, 1992, Byrne, 2016) was employed in the analysis and additionally, (ii) an appropriate parcelling technique was applied on the measurement items of the latent constructs to address this issue (J. Wang and Wang, 2012). The test results of the Bollen-Stine bootstrapping procedure have generated an insignificant $p$ value $(p>0.05)$ (Bollen and Stine, 1992, Byrne, 2016); thus, the test results of this bootstrapping procedure suggest that the model fit the data very well.

The item-pairs parcelling method (Hau and Marsh, 2004, Marsh and O'Neill, 1984) was adopted for the PE and EOU constructs because the measurement items of each construct did not have similar wording; however, in contrast, the measurement items of the REW construct had similar wordings and thus, the content similarity approach (Nasser,Takahashi and Benson, 1997) was adopted to consolidate pairs of items with similar wording. In the itempairs parcelling method, a parcel is created by calculating the average of each pair of contiguous sequential items whereas in the content similarity approach, a parcel is created by calculating the average of each pair of items that have similar content. Table 4 displays the constructs' values for Cronbach Alpha, composite reliability (CR) and average variance extracted (AVE) and since they are above the thresholds of $0.7,0.7$ and 0.5 , respectively, convergent validity is not an issue in our data set. In addition, discriminant validity is not an issue as the square roots of the AVE of each construct (listed on the diagonal) are higher than their correlations (Malhotra, 2010, Li- tze Hu and Bentler, 1999b).

[Insert Table 4] 


\section{Multigroup invariance of the measurement model}

The process for the multigroup invariance test of the measurement and structural model comprises identifying a baseline model and then comparing the model fit indices and CFI values of the unconstrained and constrained versions of the model (Bentler and $\mathrm{Wu}, 2005)$. A $\Delta$ CFI difference below 0.01 would indicate that the measurement or structural model is multigroup invariant (Byrne, 2016, Cheung and Rensvold, 2002). The results of the final measurement model $(\mathrm{GFI}=0.953 ; \mathrm{AGFI}=0.927 ; \mathrm{NFI}=0.976 ; \mathrm{IFI}=0.988 ; \mathrm{TLI}=0.985$;

$\mathrm{CFI}=0.988 ; \mathrm{RMR}=0.018 ; \mathrm{RMSEA}=0.053)(\mathrm{Li}$-tze Hu and Bentler, 1999a, Byrne, 2016) and the CFI difference values between the unconstrained and constrained models $(\Delta \mathrm{CFI}=0.008)$ suggest that the measurement model is multigroup invariant. Table 5 summarises the result of the multi-group invariance test.

\section{[Insert Table 5]}

\section{Cross-validation of the structural model}

The fit indices of the baseline model for the calibration group were satisfactory $\left(\chi^{2}(\mathrm{df}=50)=\right.$ 68.307, $\mathrm{p}<0.05 ; \mathrm{CFI}=.990 ; \mathrm{RMSEA}=0.048)$. Additionally, the fit indices of the unconstrained and constrained models (RMSEA between 0.037 and 0.039 ) and insignificant $\Delta$ CFI difference values between the unconstrained and constrained models suggest that the full structural equation model (see Figure 3) is multigroup invariant. Table 6 summarises the results of the cross-validation test for the structural model.

\section{[Insert Table 6]}

\section{ANALYSIS AND RESULTS}

Structural equation modelling was used to test the path significance and magnitude of the hypothesised effects and the explanatory power of the hypothesised model. The $\mathrm{R}^{2}$ value of the structural model is $81.4 \%$ indicating that the predictors of PE explain $81.4 \%$ of its variance and thus, our research model fits the empirical data well. 
[Insert Figure 3]

Table 7 shows that as predicted in $\mathrm{H} 1$ and H2, perceived ease-of-use (EOU) and reward schemes (REW) have a significant effect on PE, a finding that is consistent with a prior research study (Jagger,Siala and Sloan, 2015). The magnitude and values of the standardised path coefficients suggest that REW $(\mathrm{SPC}=.619)$ is the most influential predictor for PE when compared to EOU (SPC=. 335).

\section{[Insert Table 7]}

A Pearson correlation test was conducted to compare learners' perceived and actual learning performance. Perceived learning is measured by the self-reported PE construct whereas actual learning performance is measured by the players' final scores in the game. Table 8 illustrates the results of the correlation test. According to Table 8, there is a significant correlation $\left(r=.389^{*} ; \mathrm{p}<0.05\right)$ between learners' perceived and actual learning performance, which further attests to the andragogical effectiveness of serious games as practice-based managerial learning tools.

\section{[Insert Table 8]}

\section{Moderators}

The effect of the moderators was tested using multigroup analyses; the subgroup categories for the multigroup analyses were derived from the moderating variables: gender and culture. Subgroup categories that accumulated to a size of less than 40 were precluded from subsequent multigroup analyses (Wolf et al., 2013, Sideridis et al., 2014). A chidifference test was then conducted to ascertain if there are significant differences in the hypothesised effect between the groups (Byrne, 2016, Homburg and Giering, 2001). Table 9 displays the results of the subgroup analyses for the various moderators.

[Insert Table 9] 


\section{Gender}

Table 9 shows that the male participants found the game easy-to-use and they perceive it to be an effective practice-based managerial learning tool; however, female participants seem to have found the game difficult to use as evidenced by the significant chi-square difference between the gender groups $\left(\Delta \chi^{2}(\mathrm{df}=1)=14.255, \mathrm{p}<0.001\right)$. The weak perception of ease of use in the female group could be ascribed to the comparatively lower gaming experience of the female participants. According to Table 10, 43.1\% of male respondents play online games often or on a daily basis, but only $12.9 \%$ of female participants possess a comparable gaming experience; thus, female participants could have experienced an episode of computer anxiety whilst playing the game. Computer anxiety is experienced when one faces a steep learning curve to get to grips with new technology (Korukonda, 2007, McElroy et al., 2007). This finding concurs with prior studies that reported significant lower ease-of-use scores for female users (compared to males) when they were evaluating a new technology (Viswanath Venkatesh and Morris, 2000, Newbery,Lean and Moizer, 2016), which substantiates the argument that female users are more likely to come under the late majority or laggards adopting group when evaluating and testing a new technology (Chau and Lung Hui, 1998, Keller and Cernerud, 2002, Laukkanen and Pasanen, 2008, Liaw, 2002, Elliott and Hall, 2005, Borrero et al., 2014, Rosenbaum and Wong, 2015).

[Insert Table 10]

The chi-square difference test between the two groups for the effect of reward (REW) was also significant $\left(\Delta \chi^{2}(\mathrm{df}=1)=14.255, \mathrm{p}<0.01\right)$ with the stronger effect emanating from the female group, which suggests that rewarding schemes could be an effective buy-in for facilitating female learners' adoption of serious games as a learning instrument. To sum up, the empirical findings support hypotheses $\mathrm{H} 3$ and H4; therefore, $\mathrm{H} 3$ and $\mathrm{H} 4$ are accepted. 


\section{Cultural moderators}

The moderating effect for learners from individualist and collectivist cultures was insignificant; thus, H5 is rejected. However, as predicted, in contrast to low uncertainty avoidance cultures, learners from high uncertainty avoidance cultures $\left(\Delta \chi^{2}(\mathrm{df}=1)=2.719, \mathrm{p}\right.$ $<0.05)$ found the serious 3D ethics game difficult to use suggesting that low uncertainty cultures are likely to come under the innovator or early adopting group when evaluating or testing a serious game, whilst their high uncertainty counterparts are likely to come under the late majority or laggards adopting group; therefore, H6 is accepted. It is worth noting that although it was not tested as a hypothesis, learners from high uncertainty avoidance cultures perceive the built-in rewarding mechanism in the game to have significantly improved their perception of a serious game as an effective andragogical, practise-based managerial learning tool. This latter finding suggests that for high uncertainty avoidance learners, the adoption of a serious game can be facilitated through a generous reward scheme. The moderating effects of the power distance cultures were insignificant and thus, $\mathrm{H} 7$ is rejected.

\section{DISCUSSION}

This research study aims to address a topical question in management education of whether learners from different cultures perceive a serious 3D ethics game (Joy and Kolb, 2009, Alice Y Kolb and Kolb, 2009, Yamazaki, 2005) to be an effective practice-based managerial learning tool. To gain a more in-depth view on the variations in the moderator effects, a pragmatic approach of visual analysis (Searing and Searing, 2015) was applied, which involves separating the cultural groups by gender, plotting the standardised path coefficient values of the predictors ease of use (EOU) and reward mechanisms (REW) on a chart for each gender-specific cultural group. The coordinates of the gender-specific cultural groups on the chart were then perused to identify if the groups converge into different visual clusters. Figure 4 illustrates the chart. 


\section{[Insert Figure 4]}

The middle point of the minimum and maximum standardised path coefficient values of the exogenous latent constructs, ease of use (0.3) and reward (0.5) were taken as cut-off points to represent the 'medium' effect of each predictor on the latent criterion variable (PE). Figure 4 shows the group categories that converged into clusters. These clusters could signify from a pragmatic point of view different bands for the amount of training and support (ease of use), and incentives (rewards) needed to engage and motivate learners from each cluster or group to adopt a serious 3D game as a learning instrument. The clusters and groups in the chart when contextualised to Rogers' adoption and diffusion theory would represent the innovative, early adopter, early majority, late majority and laggards learning category (Rogers, 2010). Each learning cluster or group will now be discussed in light of Rogers'(2010) adoption theory.

\section{Innovators and Early Adopters}

The characteristics of individuals in this learning cluster seem to fit the description of Rogers' innovator and early adopting group, which comprises heavy users of an innovative product or service (Rogers, 2010). This group could therefore represent the avid players who are likely to be open to innovations and are more likely to be receptive to a technology-mediated andragogical innovation. They can be described as self-motivated learners driven more by intrinsic motives than extrinsic ones and due to their adept gaming skills, these individuals can act as opinion or thought leaders and peer-trainers for novice learners (Frambach and Schillewaert, 2002). They would require minimal training, support, and promotional persuasion or incentivisation (Rogers, 2010) to potentially adopt and accustom themselves to a serious 3D gaming environment. Basic support in the form of user guides and online video tutorials would suffice to support learners in this learning cluster. 


\section{Early Majority}

Learners in this group are prone to adopt a new technology-mediated andragogical innovation, but they will need some form of promotional awareness and persuasion to reassure them about the effectiveness of that innovation; thus, case studies, testimonials and success stories demonstrating the innovation's effectiveness could significantly inform the adopting decisions of learners in this learning cluster. They would require some moderate training and support, for example, an instructor-led supervised lab session to ensure that they come to grips with the serious gaming environment (Pando-Garcia,Periañez-Cañadillas and Charterina, 2016). The dependence of the 'early majority' learners on instructor guidance is expected to gradually diminish as once they develop their confidence in using the serious game they would progress and use the same learning and support resources as learners in the innovators and early adopter learning cluster.

\section{Late Majority and Laggards}

Learners in the late majority learning cluster are risk-averse and reluctant to change and thus, they are likely to refrain from adopting a technology-mediated andragogical innovation. They will usually carefully monitor the progress of a new technology's diffusion and they would peruse the feedback reported by others who have tried and verified the effectiveness of that new technology. A comprehensive face-to-face training intervention, impact case studies demonstrating the successful application of the serious game, other learners' testimonials, and stats about people who have adopted the serious game could appease the uncertainties felt by the learners in this learning cluster and potentially facilitate their adoption of a serious game. The score of the reward predictor variable for this learning cluster suggests that 'late majority' learners are more extrinsically motivated than their peers in the innovators, early adopters and early majority learning clusters; thus, stronger incentives are needed to convert these learners to the adoption of a serious game as a learning instrument. 
Learners in the laggards learning group are the strugglers and stragglers when it comes to adopting a serious game as a learning instrument. They are very likely to be risk-averse and opposed to any changes to existing teaching and learning methods that they have been accustomed to and since peer pressure, social norms and traditions would significantly shape their adoption of a technology-mediated andragogical innovation, converting learners from this learning cluster to adopt a serious game would be a monumental challenge. Like their late majority counterparts, reassuring stats about people who adopted the serious game, a comprehensive face-to-face training intervention for an extended period, and peer pressure could attenuate their concerns and potentially facilitate their adoption of a serious game as a learning instrument. Additionally, learners from the the 'laggards' learning category seem to be the most extrinsically motivated when compared to the other groups, which is reflected by the highest score of the reward predictor variable.

There is a plethora of articles in the management education literature that have ascribed the shortage of 'workplace-ready' business graduates to the bland traditional instructional approaches that fail to bridge the gap between theory and practice (Pfeffer and Fong, 2004, Daspit and D'Souza, 2012, Ashkanasy, 2006, Salas,Wildman and Piccolo, 2009). Serious games were proposed as technology-mediated andragogical alternatives to attenuate the gap between theory and practice, and they were eventually verified to be effective andragogical tools for learning practical managerial skills (Salas,Wildman and Piccolo, 2009), a finding that resonates with the findings of this research study. However, despite being a topical issue, the literature has been quiet about studies investigating learners' adoption of technologymediated andragogical innovations such as serious games from a cultural angle; thus, this study attempts to address this gap in the literature. The empirical results from this study suggest that when gender is taken into account, there are variations in how learners from different cultures perceive the effectiveness of a serious game as a practice-based managerial 
learning instrument for learning practical managerial skills such as ethical decision-making. There were significant differences across cultures on how learners perceive the extent of contribution that the game's built-in reward schemes make to the learning experience. In addition, learners from some cultural groups found the game's learning curve to be steep, which could potentially have a significant impact on their decision to adopt a serious game as a managerial learning tool since ease of use was found to significantly shape users' attitudes towards a system and their intention to adopt a system on the long-term (Roca and Gagné, 2008, Visawanath Venkatesh and Speier, 2000). Computer anxiety, a key adversary of ease of use (Hackbarth,Grover and Mun, 2003, Raafat George Saadé and Kira, 2009, Sun et al., 2008) can dissipate through the provision of an appropriate training intervention (Hackbarth,Grover and Mun, 2003, V. Venkatesh,Speier and Morris, 2002, Viswanath Venkatesh and Bala, 2008); thus, the next section will provide some guidelines for incentivising, training and supporting learners from different cultures to facilitate their adoption of a serious game as a learning instrument.

\section{MANAGERIAL IMPLICATIONS}

Business schools in academic institutions contemplating the use of serious games in a crosscultural educational setting should choose games that incorporate learning tasks that align with the learning tasks taught in the traditional classroom. To provide an authentic learning experience, the learning environment of a serious game should include an immersive 3D learning environment that simulates the visual settings of the corporate environment of interest as prior research suggests that immersive learning environments can significantly impact on user experience, perceived ease of use, perceived usefulness, satisfaction, and the potential adoption of a technology (Agarwal and Karahanna, 2000, Finneran and Zhang, 2005, Novak,Hoffman and Yung, 2000, Schrader and Bastiaens, 2012). 


\section{Incentivisation and Supporting strategies to facilitate the adoption of serious games in cross-cultural educational environments}

A generic tactic that can be applied to engage and motivate extrinsically learners from

different cultures is to ensure that the serious game has various assessments and point collection mechanisms such as a self-assessment quiz at the end of each level and bonus points for collecting clues whilst they are playing the game.

The engagement of learners from the innovators and early adopters learning cluster can be further enhanced by introducing additional competitive elements in the serious game such as displaying frequent updates on the scores of 'rival' players (learners). Learners from this learning cluster would require minimal support to accustom themselves to a serious game, which can be addressed by 'how-to' user guides and online video tutorials.

Learners in the early majority learning group are inclined to eventually adopt a technologymediated andragogical innovation such as a serious game, but they would need some form of promotional awareness and persuasion to reassure them about the andragogical effectiveness of the serious game. Therefore, instructors should demonstrate in an induction session some case studies and success stories about how the serious game has improved the learning experience of a previous cohort. In addition, positive testimonials and reviews from peers could inform the adopting decisions of learners in this learning group and thus, peer reviews and testimonials, when available, should be published online on the serious game's website. Learners in this learning group would require moderate training and support such as a supervised lab session where the instructor demonstrates the controls for playing the serious game as the social presence of instructors in a training session in general was found to have a positive impact on the learning experience and technology adoption of learners (Sørebø et al., 2009, Sun et al., 2008). Once learners from the early majority learning group develop their confidence in playing the game, they are expected to use the same learning and support resources as learners from the innovators and early adopter learning groups. 
The motivate learners from the more demanding late majority learning cluster and laggards learning group, educators should introduce a marking scheme for playing the game as part of a coursework assessment and they could also use additional incentivisation strategies such as sending group emails every week that contain the names of top-scoring players to the class, nominating high-achievers for a prize, and publishing a leader board table that displays the names of the top-scoring players. In addition, since learners in these two learning categories are expected to adopt a 'wait and see' approach by monitoring the effectiveness and diffusion progress of a technological innovation before deciding on whether or not to adopt a technological innovation (Rogers, 2010, Frambach and Schillewaert, 2002), to appease the uncertainties felt by these sceptic learners towards the serious game and potentially facilitate their adoption of the serious game as a learning instrument, instructors should in an induction session go through impact case studies that demonstrate the successful application of the serious game. In addition, instructors should also publish peer testimonials and reviews of a previous cohort of learners and stats about learners who have adopted the serious game. Learners from the late majority and laggards learning groups would require comprehensive support in the form of face-to-face training interventions for an extended period or live chats and support on social media networks. Since social influence from peers can appease the concerns of learners from the late majority and laggards learning category and inform their decision to adopt an innovation (Rogers, 2010, Frambach and Schillewaert, 2002), instructors should foster a collaborative and social learning environment by involving other learners as peer-trainers in the training sessions as such a practice was found to dissipate computer anxiety, instill positive attitudes towards a new system, and increase users' intention to adopt a system (Viswanath Venkatesh and Bala, 2008, Visawanath Venkatesh and Speier, 2000, Jasperson,Carter and Zmud, 2005, Huber and Lewis, 2010, Francescato et al., 2006, Raafat George Saadé and Kira, 2009, Hackbarth,Grover and Mun, 2003, Sun et al., 2008, Ke, 
2008b). The instructor should ideally choose peer-trainers from the elite innovators and early adopters learning cluster, which comprises male learners from low uncertainty avoidance, low power distance, individualistic, collectivist and to a lesser extent high power distance cultures.

\section{Transferability and transferring skills}

The primary aim of serious games is to facilitate the learning and transfer of soft and core skills and concepts in a discipline to corporate environments. Transferability stipulates that skills, knowledge and behaviours can be applied with little or no adaptation to any new task or context (Detterman and Sternberg, 1993, Berliner and Calfee, 1996, Bransford and Schwartz, 1999), and it has been described as an ongoing challenge (Klemp, 1977):

"The experience of higher education, it is commonly held, better prepares one to take on the mantle of career and life... And yet, soon after embarking on their new careers and lives .., new graduates discover that the knowledge and ability acquired in school are not enough, that something is missing in their preparation that prevents them from translating what they have learned into effective performance."

In this respect, serious games may replicate real-life tasks and contexts, but if a serious game cannot imitate the non-perceptual task components, the transferability of skills, knowledge and behaviour could become questionable. However, this shortcoming does not apply to the cognitive or emotional aspects of learning, as they are less dependent on the physical game design. Thus, one can contend that an immersive and interactive 3D learning environment that involves the application of ethical skills to real-world scenarios may produce the pertinent cognitive or emotional stimuli of transferability; consequently, a learner can then simply transfer the ethical skills and knowledge that were acquired from a serious game to real-life situations, without being sensitive and responsive to context. 
Instructors contemplating the use of serious games to teach ethical skills and knowledge should take the meta-competencies of a learner and context into account. This objective could be achieved by discerning the sensitive and subtle similarities and differences between social and cognitive settings, examining and identifying the cognitive instruments (which could potentially be culturally informed) that enable a learner to extend or adapt his or her previous knowledge repertoire to a new situation and, investigating profoundly the attitudes or dispositions that support an individual's learning receptiveness and sensitivity.

\section{CONCLUSION}

The empirical findings of this study bear key implications for educators contemplating the use of serious 3D games as an adjunct or alternative teaching instrument to deliver practicebased managerial courses in a culturally diverse educational and training environment. There is an emerging trend of using serious games to recruit and train staff in corporate environments (Boinodiris, 2010, Pando-Garcia,Periañez-Cañadillas and Charterina, 2016, Allal-Chérif and Makhlouf, 2016); thus, business graduates who are familiarised with serious gaming environments will feel prepared for game-based training environments that could be potentially adopted by a future employer. The quantitative data was collected through a crosssectional survey, which means that the effects between the exogeneous and endogenous constructs should not be strictly interpreted as a cause and effect relationship and alternative explanations should be considered. Future studies should perform a longitudinal survey study to confirm whether the hypothesised effects and findings of this study will persist and replicate over time. The participants in this study were undergraduate business students and thus, the results may vary in a graduate student cohort. A future study should conduct a qualitative research study that captures the learners' profound experiences, emotions and opinions about a serious game as alternative andragogy. This will provide valuable insight 
into user experiences with serious games, which cannot be gauged or captured with quantitative measurement instruments. In addition, future research should attempt to validate our conceptual model using a sample of business professionals in a corporate environment to ascertain whether these findings extrapolate to professional practice, and educators should also investigate whether serious game-based learning environments can become a costeffective replacement for work-based training schemes and job placements.

\section{Acknowledgements}

The authors would like to thank both ORT and the University of Roehampton University for supporting the research study as the software development was part of a matched funding project between the University of Roehampton, and a European NGO, ORT France.

The authors would also like to express special thanks and gratitude to Dr Suzy Jagger who is the brain-parent of the serious game for granting the authors permission to use the serious game and the data set for this research study. The authors would also like to thank the two "anonymous" reviewers for their invaluable and substantive insights, comments and constructive feedback on how to improve the first version of the manuscript that was submitted to this journal. 


\section{REFERENCES}

Adler, N.J. (2011) 'Leading beautifully: The creative economy and beyond'. Journal of Management Inquiry, 20 (3), pp. 208-221.

Afari, E., Aldridge, J. M., Fraser, B. J., and Khine, M. S. (2013) 'Students perceptions of the learning environment and attitudes in game-based mathematics classrooms'. Learning Environments Research, 16 (1), pp. 131-150.

Agarwal, R. and Karahanna, E. (2000) 'Time flies when you're having fun: cognitive absorption and beliefs about information technology usage 1'. MIS quarterly, 24 (4), pp. 665-694.

Ajzen, I. (1988) Attitudes, Personality and Behavior. Milton Keynes: Open University Press.

Ajzen, I. (2002) 'Perceived behavioral control, self-efficacy, locus of control, and the theory of planned behavior'. Journal of Applied Social Psychology, 32 (4), pp. 665-683.

Al-Senaidi, S., Lin, L. and Poirot, J. (2009) 'Barriers to adopting technology for teaching and learning in Oman'. Computers \& Education, 53 (3), pp. 575-590.

Alavi, M., Yoo, Y. and Vogel, D.R. (1997) 'Using information technology to add value to management education'. Academy of Management, 40 (6), pp. 1310-1333.

Allal-Chérif, O. and Makhlouf, M. (2016) 'Using serious games to manage knowledge: The SECI model perspective'. Journal of Business Research, 69 (5), pp. 1539-1543.

Anderson, J.C. and Gerbing, D.W. (1992) 'Assumptions and comparative strengths of the two-step approach comment on Fornell and Yi'. Sociological Methods \& Research, 20 (3), pp. 321-333.

Arbaugh, J., DeArmond, S. and Rau, B.L. (2013) 'New uses for existing tools? A call to study on-line management instruction and instructors'. Academy of Management Learning \& Education, 12 (4), pp. 635-655.

Armstrong, S.J. (2011) 'From the editors: Continuing our quest for meaningful impact on management practice'. Academy of Management Learning \& Education, 10 (2), pp. 181-187.

Ashkanasy, N.M. (2006) 'Introduction: Arguments for a more grounded approach in management education'. Academy of Management Learning \& Education, 5 (2), pp. 207-208.

Auyeung, P. and Sands, J. (1996) 'A cross cultural study of the learning style of accounting students'. Accounting \& Finance, 36 (2), pp. 261-274.

Baden, D. and Higgs, M. (2015) 'Challenging the perceived wisdom of management theories and practice'. Academy of Management Learning \& Education, 14 (4), pp. 539-555.

Bartunek, J.M. (2014) 'From the editors: Honoring the legacy of Chris Argyris by devoting attention to how managers learn'. Academy of Management Learning \& Education, 13 (1), pp. 1-4.

Bentler, P.M. and Wu, E.J. (2005) 'EQS 6.1 for Windows'. Structural Equations Program Manual. Encino, CA: Multivariate Software.

Berliner, D.C. and Calfee, R.C. (1996) Handbook of Educational Psychology. Routledge, New York, USA.

Bhattacherjee, A. (1998) 'Managerial Influences on Intraorganizational Information Technology Use: A Principal-Agent Model'. Decision Sciences, 29 (1), pp. 139-162.

Bledow, R., Carette, B., Kühnel, J. and Bister, D. (2017) 'Learning From Others' Failures: The Effectiveness of Failure Stories for Managerial Learning'. Academy of Management Learning \& Education, 16 (1), pp. 39-53.

Bloom, S. (2009) 'Game-based learning'. Professional Safety, 54 (7), pp. 18-21.

Boinodiris, P. (2010) IBM - CityOne Game. Available at: https://www.ibm.com/software/solutions/soa/newsletter/aug10/cityone.html

http://www-01.ibm.com/software/solutions/soa/newsletter/aug10/cityone.html (Accessed: 09/11/2017).

Bollen, K.A. and Stine, R.A. (1992) 'Bootstrapping Goodness-of-Fit Measures in Structural Equation Models'. Sociological Methods \& Research, 21 (2), pp. 205-229.

Borrero, J. D., Yousafzai, S. Y., Javed, U., and Page, K. L. (2014) 'Expressive participation in Internet social movements: Testing the moderating effect of technology readiness and sex on student SNS use'. Computers in Human Behavior, 30, pp. 39-49. 
Bransford, J.D. and Schwartz, D.L. (1999) 'Chapter 3: Rethinking Transfer: A Simple Proposal With Multiple Implications'. Review of Research in Education, 24 (1), pp. 61-100.

Bridget, B. and Andrea, T. (2011) 'Do avatars dream of electronic picket lines?: The blurring of work and play in virtual environments'. Information Technology \& People, 24 (1), pp. 26-45.

Bryman, A. and Bell, E. (2015) Business Research Methods, Oxford University Press, New York, USA.

Byrne, B.M. (2016) Structural EquationModeling with AMOS: Basic Concepts, Applications, and Programming. New York: Routledge.

Cajiao, J. and Burke, M.J. (2016) 'How Instructional Methods Influence Skill Development in Management Education'. Academy of Management Learning \& Education, 15 (3), pp. 508524.

Chaffey, D. and Ellis-Chadwick, F. (2016) Digital marketing: Strategy, Implementation and Practice. 6th ed. Pearson Education Limited, Malaysia.

Chau, P.Y.K. and Lung Hui, K. (1998) 'Identifying early adopters of new IT products: A case of Windows 95'. Information \& Management, 33 (5), pp. 225-230.

Cheung, G.W. and Rensvold, R.B. (2002) 'Evaluating goodness-of-fit indexes for testing measurement invariance'. Structural equation modeling, 9 (2), pp. 233-255.

Churchill, G.A. and lacobucci, D. (2005) Marketing Research: Methodological Foundations. Thomson/South-Western, Mason, Ohio.

Cudeck, R. and Browne, M.W. (1983) 'Cross-validation of covariance structures'. Multivariate Behavioral Research, 18 (2), pp. 147-167.

Daspit, J.J. and D'Souza, D.E. (2012) 'Using the community of inquiry framework to introduce wiki environments in blended-learning pedagogies: Evidence from a business capstone course'. Academy of Management Learning \& Education, 11 (4), pp. 666-683.

Davis, F.D. (1993) 'User acceptance of information technology: system characteristics, user perceptions and behavioral impacts', International Journal of Man-Machine Studies, 38(3), pp. 475-487.

Davis, F.D., Bagozzi, R.P. and Warshaw, P.R. (1989) 'User Acceptance of Computer-Technology - a Comparison of 2 Theoretical-Models'. Management Science, 35 (8), pp. 982-1003.

Dean, K.L. and Beggs, J.M. (2006) 'University Professors and Teaching Ethics: Conceptualisations and Expectations'. Journal of Management Education, 30 (1), pp. 15-44.

Detterman, D.K. and Sternberg, R.J. (1993) Transfer on Trial: Intelligence, Cognition, and Instruction. Westport, CT, US: Ablex Publishing.

Ebel, R.L. and Frisbie, D. (1991) Essentials of Educational Measurement. Fifth ed. Englewood Cliffs, NJ. Prentice-Hall.

Egri, C.P. (2013) 'From the editors: Context matters in management education scholarship'. Academy of Management Learning \& Education, 12 (2), pp. 155-157.

Elliott, K.M. and Hall, M.C. (2005) 'Assessing Consumers' Propensity to Embrace Self-service Technologies: Are There Gender Differences?'. Marketing Management Journal, 15 (2), pp. 98-107.

Finneran, C.M. and Zhang, P. (2005) 'Flow in computer-mediated environments: promises and challenges'. Communications of the Association for Information Systems, 15 (1), pp. 82-101.

Foxall, G.R. and Bhate, S. (1993) 'Cognitive styles and personal involvement of market initiators for 'healthy'food brands: implications for adoption theory'. Journal of Economic Psychology, 14 (1), pp. 33-56.

Frambach, R.T. and Schillewaert, N. (2002) 'Organizational innovation adoption: a multi-level framework of determinants and opportunities for future research'. Journal of Business Research, 55 (2), pp. 163-176.

Francescato, D., Porcelli, R., Mebane, M., Cuddetta, M., Klobas, J. and Renzi, P. (2006) 'Evaluation of the efficacy of collaborative learning in face-to-face and computer-supported university contexts'. Computers in Human Behavior, 22 (2), pp. 163-176. 
Geddes, D. (2009) 'How am I doing? Exploring on-line gradebook monitoring as a self-regulated learning practice that impacts academic achievement'. Academy of Management Learning \& Education, 8(4), pp. 494-510.

Gino, F. and Staats, B. (2015) 'Why organizations don't learn'. Harvard Business Review, 93(11), pp. 110-118.

Hackbarth, G., Grover, V. and Mun, Y.Y. (2003) 'Computer playfulness and anxiety: positive and negative mediators of the system experience effect on perceived ease of use'. Information \& Management, 40(3), pp. 221-232.

Hainey, T.,Connolly, T. M., Stansfield, M. and Boyle, E. A. (2011) 'Evaluation of a game to teach requirements collection and analysis in software engineering at tertiary education level'. Computers \& Education, 56(1), pp. 21-35.

Hair, J. F., Black, W. C., Babin, B. J., Anderson, R. E. and Tatham, R. (2010) 'Multivariate Data Analysis: Pearson Education'. Upper Saddle River, New Jersey.

Hardesty, D.M. and Bearden, W.O. (2004) 'The use of expert judges in scale development: Implications for improving face validity of measures of unobservable constructs'. Journal of Business Research, 57(2), pp. 98-107.

Hardy, C. and Tolhurst, D. (2014) 'Epistemological beliefs and cultural diversity matters in management education and learning: A critical review and future directions'. Academy of Management Learning \& Education, 13(2), pp. 265-289.

Hau, K.T. and Marsh, H.W. (2004) 'The use of item parcels in structural equation modelling: Nonnormal data and small sample sizes'. British Journal of Mathematical and Statistical Psychology, 57(2), pp. 327-351.

Heimbeck, D., Frese, M., Sonnentag, S. and Keith, N. (2003) 'Integrating errors into the training process: The function of error management instructions and the role of goal orientation'. Personnel Psychology, 56(2), pp. 333-361.

Hofstede, G. (2003) Culture's consequences: Comparing Values, Behaviors, Institutions and Organizations Across Nations, Sage Publications, Thousand Oaks, California.

Hofstede, G. (2010) Cultures and Organizations: Software of the Mind. Third ed. McGraw-Hill Education, New York, USA.

Hofstede, G. and McCrae, R.R. (2004) 'Personality and culture revisited: Linking traits and dimensions of culture'. Cross-Cultural Research, 38(1), pp. 52-88.

Homburg, C. and Giering, A. (2001) 'Personal characteristics as moderators of the relationship between customer satisfaction and loyalty-an empirical analysis'. Psychology \& Marketing, 18(1), pp. 43-66.

House, R. J., Hanges, P. J., Javidan, M., Dorfman, P. W. and Gupta, V. (2004) Culture, Leadership, and Organizations: The GLOBE study of 62 societies. Sage Publications,Thousand Oaks, United States.

Hu, L.-t. and Bentler, P.M. (1999a) 'Cutoff criteria for fit indexes in covariance structure analysis: conventional criteria versus new alternatives'. Structural Equation Modeling, 6(1), pp. 1-55.

$\mathrm{Hu}$, L.t. and Bentler, P.M. (1999b) 'Cutoff criteria for fit indexes in covariance structure analysis: Conventional criteria versus new alternatives'. Structural Equation Modeling: $A$ Multidisciplinary Journal, 6(1), pp. 1-55.

Huber, G.P. and Lewis, K. (2010) 'Cross-understanding: Implications for group cognition and performance'. Academy of Management Review, 35(1), pp. 6-26.

Hwang, D.,Staley, B., Te Chen, Y. and Lan, J. (2008) 'Confucian culture and whistle-blowing by professional accountants: An exploratory study'. Managerial Auditing Journal, 23(5), pp. 504-526.

lacobucci, D.,Posavac, S. S., Kardes, F. R., Schneider, M. and Popovich, D. (2015) 'The median split: Robust, refined, and revived'. Journal of Consumer Psychology, 25(4), pp. 690-704.

Jagger, S., Siala, H. and Sloan, D. (2015) 'It's All in the Game: A 3D Learning Model for Business Ethics'. Journal of Business Ethics, 137(2), pp. 383-403. 
Jasperson, J.S., Carter, P.E. and Zmud, R.W. (2005) 'A comprehensive conceptualization of postadoptive behaviors associated with information technology enabled work systems'. MIS Quarterly, 29(3), pp. 525-557.

Joy, S. and Kolb, D.A. (2009) 'Are there cultural differences in learning style?'. International Journal of Intercultural Relations, 33(1), pp. 69-85.

Kapp, K.M. (2012) The Gamification of Learning and Instruction: Game-based Methods and Strategies for Training and Education. John Wiley \& Sons,New York, United States.

Kawalek, J.P. and Hart, D. (2007) 'Managing e-learning group processes using teleological enquiring principles'. Journal of Information Technology, 22(2), pp. 133-151.

Ke, F. (2008a) 'A case study of computer gaming for math: Engaged learning from gameplay?'. Computers \& Education, 51(4), pp. 1609-1620.

Ke, F. (2008b) 'Computer games application within alternative classroom goal structures: cognitive, metacognitive, and affective evaluation'. Educational Technology Research and Development, 56(5-6), pp. 539-556.

Kebritchi, M., Hirumi, A. and Bai, H. (2010) 'The effects of modern mathematics computer games on mathematics achievement and class motivation'. Computers \& Education, 55(2), pp. 427443.

Keller, C. and Cernerud, L. (2002) 'Students' Perceptions of E-learning in University Education'. Journal of Educational Media, 27(1-2), pp. 55-67.

Klemp, G.O. (1977), "Three factors of success in the world of work: implications for curriculum in higher education", In Bermilze, D. (Ed), Relating Work and Education: Current Issues in Higher Education, Jossey-Bass, San Francisco, CA.

Kline, R.B. (2015) Principles and practice of structural equation modeling. Guilford publications.

Kline, T.J. (ed.) (2005) Classical Test Theory: Assumptions, Equations, Limitations, and Item Analyses. Thousand Oaks,CA: SAGE Publications, Inc.

Klopfer, E., Osterweil, S. and Salen, K. (2009) 'Moving learning games forward'. Cambridge, MA: The Education Arcade.

Kolb, A.Y. and Kolb, D.A. (2009) "Experiential learning theory: A dynamic, holistic approach to management learning, education and development", In Armstrong, S. J. and Fukami,C. V. (Eds), The SAGE Handbook of Management Learning, Education and Development, Sage, Thousand Oaks, USA, pp 42-68.

Kolb, D. (1984) Experiential Learning as the Science of Learning and Development, Englewood Cliffs, NJ: Prentice Hall.

Korukonda, A.R. (2007) 'Differences that do matter: A dialectic analysis of individual characteristics and personality dimensions contributing to computer anxiety'. Computers in Human Behavior, 23 (4), pp. 1921-1942.

Laukkanen, T. and Pasanen, M. (2008) 'Mobile banking innovators and early adopters: How they differ from other online users?'. Journal of Financial Services Marketing, 13 (2), pp. 86-94.

Lean, J., Moizer, J. and Newbery, R. (2014) 'Enhancing the impact of online simulations through blended learning: A critical incident approach'. Education+ Training, 56 (2/3), pp. 208-218.

Lee, Y. and Choi, J. (2011) 'A review of online course dropout research: Implications for practice and future research'. Educational Technology Research and Development, 59 (5), pp. 593-618.

Lee, Y., Choi, J. and Kim, T. (2013) 'Discriminating factors between completers of and dropouts from online learning courses'. British Journal of Educational Technology, 44 (2), pp. 328-337.

Leemkuil, H. and De Jong, T. (2012) 'Adaptive advice in learning with a computer-based knowledge management simulation game'. Academy of Management Learning \& Education, 11 (4), pp. 653-665.

Liaw, S.-S. (2002) 'An Internet survey for perceptions of computers and the World Wide Web: relationship, prediction, and difference'. Computers in Human Behavior, 18 (1), pp. 17-35.

Liu, C.-C., Cheng, Y.-B. and Huang, C.-W. (2011) 'The effect of simulation games on the learning of computational problem solving'. Computers \& Education, 57 (3), pp. 1907-1918. 
Malhotra, N.K. (2010) Marketing Research : An Applied Orientation. Sixth ed. London: Prentice Hall. Mar, R.A. (2011) 'The neural bases of social cognition and story comprehension'. Annual Review of Psychology, 62(1), pp. 103-134.

Marsh, H.W. and O'Neill, R. (1984) 'Self description questionnaire III: the construct validity of multidimensional self-concept ratings by late adolescents'. Journal of Educational Measurement, 21 (2), pp. 153-174.

McElroy, J. C., Hendrickson, A. R., Townsend, A. M. and DeMarie, S. M. (2007) 'Dispositional factors in internet use: personality versus cognitive style'. MIS Quarterly, 31 (4), pp. 809-820.

Michaelson, C. (2016) 'A novel approach to business ethics education: Exploring how to live and work in the 21st century'. Academy of Management Learning \& Education, 15 (3), pp. 588606.

Moshavi, D. (2001) '“Yes and...": introducing improvisational theatre techniques to the management classroom', Journal of Management Education, 25 (4), pp. 437-449.

Murnane, S. and Browne, A. (2016) 'From experience to knowledge in professional IT management education: exploring the applicability of classroom learning to real-life contexts'. The Irish Journal of Management, 35 (2), pp. 165-175.

Mustar, P. (2009) 'Technology management education: Innovation and entrepreneurship at MINES ParisTech, a leading French engineering school'. Academy of Management Learning \& Education, 8 (3), pp. 418-425.

Nasser, F., Takahashi, T. and Benson, J. (1997) 'The structure of test anxiety in Israeli-Arab high school students: An application of confirmatory factor analysis with miniscales'. Anxiety, Stress, and Coping, 10 (2), pp. 129-151.

Neville, K., Heavin, C. and Walsh, E. (2005) 'A case in customizing e-learning'. Journal of Information Technology, 20 (2), pp. 117-129.

Newbery, R., Lean, J. and Moizer, J. (2016) 'Evaluating the impact of serious games: the effect of gaming on entrepreneurial intent'. Information Technology \& People, 29 (4), pp. 733-749.

Newbery, R., Lean, J., Moizer, J. and Haddoud, M. (2018) 'Entrepreneurial identity formation during the initial entrepreneurial experience: The influence of simulation feedback and existing identity'. Journal of Business Research, 85, pp. 51-59.

Nielsen, A. (2009) 'How teens use media. A Nielsen report on the myths and realities of teen media trends'.[Accessed 17/04/2019], URL: http://www.nmprevention.org/Project_Docs/Nielsen_HowTeensUseMedia_June2009.pdf.

Novak, T.P., Hoffman, D.L. and Yung, Y.-F. (2000) 'Measuring the customer experience in online environments: A structural modeling approach'. Marketing Science, 19 (1), pp. 22-42.

O'Brien, R.M. (2007) 'A Caution Regarding Rules of Thumb for Variance Inflation Factors'. Quality \& Quantity, 41 (5), pp. 673-690.

Pando-Garcia, J., Periañez-Cañadillas, I. and Charterina, J. (2016) 'Business simulation games with and without supervision: An analysis based on the TAM model'. Journal of Business Research, 69 (5), pp. 1731-1736.

Papagiannidis, S. Pantano, E., See-To, E. WK.,Dennis, C. and Bourlakis, M. (2017) 'To immerse or not? Experimenting with two virtual retail environments'. Information Technology \& People, 30 (1), pp. 163-188.

Papastergiou, M. (2009) 'Digital game-based learning in high school computer science education: Impact on educational effectiveness and student motivation'. Computers \& Education, 52 (1), pp. 1-12.

Pasin, F. and Giroux, H. (2011) 'The impact of a simulation game on operations management education'. Computers \& Education, 57 (1), pp. 1240-1254.

Pfeffer, J. and Fong, C.T. (2004) 'The business school 'business': Some lessons from the US experience'. Journal of Management Studies, 41 (8), pp. 1501-1520. 
Phan, P.H., Siegel, D.S. and Wright, M. (2009) 'New developments in technology management education: Background issues, program initiatives, and a research agenda'. Academy of Management Learning \& Education, 8 (3), pp. 324-336.

Podsakoff, P. M.,MacKenzie, S. B., Lee, J. and Podsakoff, N. P. (2003) 'Common method biases in behavioral research: a critical review of the literature and recommended remedies'. Journal of Applied Psychology, 88 (5), pp. 879-903.

Pratchett, R. (2005) Gamers in the UK: Digital play, digital lifestyles. BBC, ,London,UK.

Renda dos Santos, L.M. and Okazaki, S. (2016) 'Planned e-learning adoption and occupational socialisation in Brazilian higher education'. Studies in Higher Education, 41 (11), pp. 19741994.

Roca, J.C. and Gagné, M. (2008) 'Understanding e-learning continuance intention in the workplace: A self-determination theory perspective'. Computers in Human Behavior, 24 (4), pp. 15851604.

Rogers, E.M. (2010) Diffusion of innovations. 4th ed. Simon and Schuster, New York, USA.

Rosenbaum, M.S. and Wong, I.A. (2015) 'If you install it, will they use it? Understanding why hospitality customers take "technological pauses" from self-service technology'. Journal of Business Research, 68 (9), pp. 1862-1868.

Saadé, R. and Bahli, B. (2005) 'The impact of cognitive absorption on perceived usefulness and perceived ease of use in on-line learning: an extension of the technology acceptance model'. Information \& Management, 42 (2), pp. 317-327.

Saadé, R.G. and Kira, D. (2009) 'Computer anxiety in e-learning: The effect of computer self-efficacy'. Journal of Information Technology Education, 8(1), pp. 177-191.

Salas, E., Wildman, J.L. and Piccolo, R.F. (2009) 'Using simulation-based training to enhance management education'. Academy of Management Learning \& Education, 8 (4), pp. 559573.

Schrader, C. and Bastiaens, T.J. (2012) 'The influence of virtual presence: Effects on experienced cognitive load and learning outcomes in educational computer games'. Computers in Human Behavior, 28 (2), pp. 648-658.

Searing, E. and Searing, D.R. (2015) Practicing Professional Ethics in Economics and Public Policy. Springer,Dordrecht, Netherlands.

Shafer, W.E. and Simmons, R.S. (2011) 'Effects of organizational ethical culture on the ethical decisions of tax practitioners in mainland China'. Accounting, Auditing \& Accountability Journal, 24 (5), pp. 647-668.

Shen, C.-Y. and Chu, H.-P. (2014) Published. 'The relations between interface design of digital gamebased learning systems and flow experience and cognitive load of learners with different levels of prior knowledge'. International Conference on Cross-Cultural Design, 2014. Springer, pp.574-584.

Sideridis, G.,Simos, P., Papanicolaou, A. and Fletcher, J. (2014) 'Using structural equation modeling to assess functional connectivity in the brain: Power and sample size considerations'. Educational and Psychological Measurement, 74 (5), pp. 733-758.

Siemer, J. and Angelides, M.C. (1997) 'Integrating an intelligent tutoring facility into a gaming simulation environment'. Journal of Information Technology, 12 (3), pp. 207-222.

Smith, N.C., Simpson, S.S. and Huang, C.-Y. (2007) 'Why managers fail to do the right thing: An empirical study of unethical and illegal conduct'. Business Ethics Quarterly, 17 (4), pp. 633667.

Sørebø, Ø.,Halvari, H.,Gulli, V. F. and Kristiansen, R. (2009) 'The role of self-determination theory in explaining teachers' motivation to continue to use e-learning technology'. Computers \& Education, 53 (4), pp. 1177-1187.

Straub, E.T. (2009) 'Understanding technology adoption: Theory and future directions for informal learning'. Review of Educational Research, 79 (2), pp. 625-649. 
Sun, P.C.,Tsai, R. J., Finger, G., Chen, Y. Y. and Yeh, D. (2008) 'What drives a successful e-Learning? An empirical investigation of the critical factors influencing learner satisfaction'. Computers \& Education, 50 (4), pp. 1183-1202.

Sung, H.-Y. and Hwang, G.-J. (2013) 'A collaborative game-based learning approach to improving students' learning performance in science courses'. Computers \& Education, 63 43-51.

Tabachnick, B.G. and Fidell, L.S. (2007) Using Multivariate Statistics. Fifth ed. London: Pearson/Allyn \& Bacon.

Tobias, S., Fletcher, J.D. and Wind, A.P. (2014) "Game-based learning", In Spector,J. M.,Merrill,M. D., Elen, J. and Bishop, M. J. (Eds), Handbook of Research on Educational Communications and Technology. Springer, New York, USA, pp. 485-503.

Towler, M., Lean, J. and Moizer, J. (2009) 'An exploration of student perception of a business simulation game'. International Journal of Management Education, 7 (2), pp. 69-79.

Tuncalp, S. (1988) 'The marketing research scene in Saudi Arabia'. European Journal of Marketing, 22 (5), pp. 15-22.

Venkatesh, V. (1999) 'Creation of favorable user perceptions: exploring the role of intrinsic motivation'. MIS Quarterly, 23 (2), pp. 239-260.

Venkatesh, V. and Bala, H. (2008) 'Technology acceptance model 3 and a research agenda on interventions'. Decision Sciences, 39 (2), pp. 273-315.

Venkatesh, V. and Morris, M.G. (2000) 'Why don't men ever stop to ask for directions? Gender, social influence, and their role in technology acceptance and usage behavior'. MIS Quarterly, 24(1), 115-139.

Venkatesh, V. and Speier, C. (2000) 'Creating an effective training environment for enhancing telework'. International Journal of Human-Computer Studies, 52 (6), pp. 991-1005.

Venkatesh, V., Speier, C. and Morris, M.G. (2002) 'User acceptance enablers in individual decision making about technology: Toward an integrated model'. Decision Sciences, 33 (2), pp. $297-$ 316.

Verzat, C., Byrne, J. and Fayolle, A. (2009) 'Tangling with spaghetti: Pedagogical lessons from games'. Academy of Management Learning \& Education, 8 (3), pp. 356-369.

Walden, E.A. and Browne, G.J. (2009) 'Sequential adoption theory: a theory for understanding herding behavior in early adoption of novel technologies'. Journal of the Association for Information Systems, 10 (1), pp. 31-62.

Waller, M.J., Lei, Z. and Pratten, R. (2014) 'Focusing on teams in crisis management education: An integration and simulation-based approach'. Academy of Management Learning \& Education, 13 (2), pp. 208-221.

Wang, J. and Wang, X. (2012) Structural Equation Modeling: Applications Using Mplus, Wiley, Hoboken, USA.

Wang, T.-L. and Tseng, Y.-F. (2014) Published. 'An empirical study: Develop and evaluation a mobile serious game on environmental education'. Computer Science \& Education (ICCSE), 2014 9th International Conference on, 2014. IEEE, pp.311-315.

Whitaker, J., New, J.R. and Ireland, R.D. (2016) 'MOOCs and the Online Delivery of Business Education What's new? What's not? What now?'. Academy of Management Learning \& Education, 15 (2), pp. 345-365.

Whitton, N. (2012) 'The place of game-based learning in an age of austerity'. Electronic Journal of eLearning, 10 (2), pp. 249-256.

Wolf, E. J.,Harrington, K. M., Clark, S. L. and Miller, M. W. (2013) 'Sample size requirements for structural equation models: An evaluation of power, bias, and solution propriety'. Educational and Psychological Measurement, 73 (6), pp. 913-934.

Wolfe, J. (1997) 'The effectiveness of business games in strategic management course work'. Simulation \& Gaming, 28 (4), pp. 360-376. 
Wu, W-H, Hsiao, H-C, Wu, P-L, Lin, C-H and Huang, S-H. (2012) 'Investigating the learning-theory foundations of game-based learning: a meta-analysis'. Journal of Computer Assisted Learning, 28 (3), pp. 265-279.

Yamazaki, Y. (2005) 'Learning styles and typologies of cultural differences: A theoretical and empirical comparison'. International Journal of Intercultural Relations, 29 (5), pp. 521-548.

Yang, Y.-T.C. (2012) 'Building virtual cities, inspiring intelligent citizens: Digital games for developing students' problem solving and learning motivation'. Computers \& Education, 59 (2), pp. 365377.

Yusoff, A., Crowder, R. and Gilbert, L. (2010) Published. 'Validation of serious games attributes using the technology acceptance model'. Games and Virtual Worlds for Serious Applications (VSGAMES), 2010 Second International Conference on, 2010. IEEE, pp.45-51.

Zhou, Z., Jin, X.-L. and Fang, Y. (2014) 'Moderating role of gender in the relationships between perceived benefits and satisfaction in social virtual world continuance'. Decision Support Systems, pp. 65, 69-79. 
Table 1: Demographic profiles, cultural orientations, work and gaming experience of respondents

\begin{tabular}{llll}
\hline Variable & Description & Frequency & Percentage \\
\hline Gender & Male & 123 & 38.6 \\
& Female & 147 & 46.1 \\
& Not specified & 49 & 15.4 \\
\hline Age (Standard Dev. $=$ 4.38) & $<17$ & 1 & 0.3 \\
& $18-24$ & 276 & 86.5 \\
& $25-34$ & 33 & 10.3 \\
& $35-44$ & 5 & 1.6 \\
& $45-54$ & 4 & 1.3 \\
\hline Individualism /Collectivism* & High individualism & 195 & 65.2 \\
& Low individualism & 104 & 34.8 \\
\hline Uncertainty Avoidance (UA)* & High UA & 124 & 41.5 \\
& Low UA & 175 & 58.5 \\
\hline Power Distance (PD)* & High PD & 117 & 39.1 \\
& Low PD & 182 & 60.9 \\
\hline Ethnicity & White & 133 & 41.7 \\
& Black & 30 & 9.4 \\
& Asian & 133 & 41.7 \\
& Middle Eastern & 7 & 2.2 \\
& Other & 16 & 5.0 \\
\hline Frequency of playing online games & Never & 80 & 25.1 \\
& Seldom & 72 & 22.6 \\
& Occasionally & 84 & 26.3 \\
& Often & 58 & 18.2 \\
& All of the Time & 25 & 7.8 \\
\hline Work experience & None & 195 & 12.1 \\
& < years & 41 & 18.5 \\
& 2 to 5 years & 59 & 7.5 \\
\hline & $>5$ years & 24 & \\
\hline
\end{tabular}

* Based on what participants reported as their country of permanent residence or home 
Table 2: Hofstede National Culture Index Scores of Countries (G. Hofstede, 2010)

\begin{tabular}{|c|c|c|c|}
\hline Countries & Power Distance* & Uncertainty Avoidance* & Individualism (vs. Collectivism)* \\
\hline Albania & 90 & 70 & 20 \\
\hline Angola & 83 & 60 & 18 \\
\hline Arabic countries & 80 & 68 & 38 \\
\hline Belgium & 65 & 94 & 75 \\
\hline Brazil & 69 & 76 & 38 \\
\hline Canada & 39 & 48 & 80 \\
\hline Chile & 63 & 86 & 23 \\
\hline China & 80 & 30 & 20 \\
\hline East Africa & 64 & 52 & 27 \\
\hline Ecuador & 78 & 67 & 8 \\
\hline Estonia & 40 & 60 & 60 \\
\hline Finland & 33 & 59 & 63 \\
\hline France & 68 & 86 & 71 \\
\hline Germany & 35 & 65 & 67 \\
\hline Ghana & 80 & 65 & 15 \\
\hline Great Britain & 35 & 35 & 89 \\
\hline Greece & 60 & 112 & 35 \\
\hline Hungary & 46 & 82 & 80 \\
\hline India & 77 & 40 & 48 \\
\hline Indonesia & 78 & 48 & 14 \\
\hline Iraq & 95 & 85 & 30 \\
\hline Italy & 50 & 75 & 76 \\
\hline Japan & 54 & 92 & 46 \\
\hline Kenya & 70 & 50 & 25 \\
\hline Korea (South) & 60 & 85 & 18 \\
\hline Latvia & 44 & 63 & 70 \\
\hline Libya & 80 & 68 & 38 \\
\hline Malawi & 70 & 50 & 30 \\
\hline Malaysia & 104 & 36 & 26 \\
\hline Morocco & 70 & 68 & 46 \\
\hline Netherlands & 38 & 53 & 80 \\
\hline Norway & 31 & 50 & 69 \\
\hline Pakistan & 55 & 70 & 14 \\
\hline Poland & 68 & 93 & 60 \\
\hline Portugal & 63 & 104 & 27 \\
\hline Russia & 93 & 95 & 39 \\
\hline
\end{tabular}




\begin{tabular}{llll} 
Singapore & 74 & 8 & 20 \\
Spain & 57 & 86 & 51 \\
Sweden & 31 & 29 & 71 \\
Switzerland & 34 & 58 & 68 \\
Taiwan & 58 & 69 & 17 \\
Thailand & 64 & 64 & 20 \\
Trinidad & 47 & 55 & 16 \\
Turkey & 66 & 85 & 37 \\
United Arab Emirates & 90 & 80 & 25 \\
United States & 40 & 46 & 91 \\
\hline
\end{tabular}

* Higher scores indicate higher levels of this dimension 
Table 3: Factor Loading for Construct Items $(N=319)$

\begin{tabular}{|c|c|c|}
\hline Construct name & Measurement item & Factor Loading \\
\hline \multirow[t]{6}{*}{ EOU $($ mean $=24.56 ;$ standard dev. $=4.59)$} & EOU1 & .748 \\
\hline & EOU2 & .713 \\
\hline & EOU3 & .786 \\
\hline & EOU4 & .815 \\
\hline & EOU5 & .806 \\
\hline & EOU6 & .765 \\
\hline \multirow[t]{4}{*}{ REW $($ mean $=16.41 ;$ standard dev. $=3.08)$} & R1 & .855 \\
\hline & R2 & .796 \\
\hline & R3 & .824 \\
\hline & R4 & .731 \\
\hline \multirow[t]{14}{*}{$\mathrm{PE}($ mean $=56.4 ;$ standard dev. $=9.94)$} & PU1 & .833 \\
\hline & PU2 & .815 \\
\hline & PU3 & .801 \\
\hline & PU4 & .835 \\
\hline & PU5 & .777 \\
\hline & PU6 & .847 \\
\hline & TS1 & .702 \\
\hline & TS2 & .805 \\
\hline & TS3 & .819 \\
\hline & TS4 & .806 \\
\hline & SL1 & .769 \\
\hline & SL2 & .810 \\
\hline & SL3 & .703 \\
\hline & SL4 & .781 \\
\hline
\end{tabular}


Table 4: Model Validity Measures

\begin{tabular}{lcccccc}
\hline & Cronbach alpha & CR & AVE & PE & EOU & REW \\
\hline PE & 0.959 & 0.957 & 0.761 & $\mathbf{0 . 8 7 2}$ & & \\
EOU & 0.898 & 0.897 & 0.744 & 0.767 & $\mathbf{0 . 8 6 2}$ & \\
REW & 0.873 & 0.891 & 0.803 & 0.876 & 0.810 & $\mathbf{0 . 8 9 6}$ \\
\hline
\end{tabular}

Note: The values on the diagonal (in bold) represent the square root of the AVEs of the individual constructs and the values underneath the diagonal are the correlations between the constructs.

Table 5: Goodness-of-fit Statistics of Multigroup Invariance for the Measurement Model

\begin{tabular}{lcccccccc}
\hline Model & $\boldsymbol{\chi}^{\mathbf{2}}$ & $\mathbf{d f}$ & $\boldsymbol{\Delta} \boldsymbol{\chi}^{\mathbf{2}}$ & $\boldsymbol{\Delta d f}$ & $\boldsymbol{p}$ & $\mathbf{C F I}$ & $\boldsymbol{\Delta C F I}$ & RMSEA \\
\hline Configural $^{169.81}$ & 98 & - & - & .000 & .980 & - & .048 \\
\hline Model 1 $^{\mathbf{a}}$ & 180.08 & 107 & 10.3 & 9 & .000 & .980 & .000 & .046 \\
\hline Model 2 $^{\mathbf{b}}$ & 212.23 & 113 & 32.131 & 15 & .000 & .973 & .007 & .053 \\
\hline
\end{tabular}

Notes: $\mathrm{a}=$ factor loadings constrained; $\mathrm{b}=$ factor loadings and intercepts constrained; $\Delta \chi^{2}=$ Difference in $\chi^{2}$ values between models; $\Delta \mathrm{df}$ $=$ Difference in number of degrees of freedom between models; $\Delta$ CFI = Difference in CFI values between models (where applicable);

Table 6: Goodness-of-fit Statistics of Multigroup Invariance for the Structural Model

\begin{tabular}{lcccccccc}
\hline Model & $\boldsymbol{\chi}^{\mathbf{2}}$ & $\mathbf{d f}$ & $\boldsymbol{\Delta} \boldsymbol{\chi}^{\mathbf{2}}$ & $\boldsymbol{\Delta d f}$ & $\boldsymbol{p}$ & $\mathbf{C F I}$ & $\boldsymbol{\Delta C F I}$ & RMSEA \\
\hline Configural $^{149.226}$ & 100 & - & - & .001 & .986 & - & .039 \\
\hline Model 1 $^{\mathbf{a}}$ & 151.678 & 109 & 2.452 & 9 & .004 & .988 & .002 & .035 \\
\hline Model 2 $^{\mathbf{b}}$ & 152.846 & 111 & 3.62 & 11 & .005 & .988 & .002 & .034 \\
\hline Model 3 $^{\mathbf{c}}$ & 155.134 & 114 & 5.91 & 14 & .006 & .988 & .002 & .034 \\
\hline Model 4 $^{\mathbf{d}}$ & 157.635 & 115 & 8.435 & 15 & .005 & .988 & .002 & .034 \\
\hline
\end{tabular}

Notes: $\mathrm{a}=$ measurement weights constrained; $\mathrm{b}=$ measurement weights and intercepts constrained; $\mathrm{c}=$ structural weights and intercepts constrained; $\mathrm{d}=$ structural covariances and structural residuals constrained; $\Delta \chi^{2}=$ Difference in $\chi^{2}$ values between models; $\Delta \mathrm{df}=$ Difference in number of degrees of freedom between models; $\triangle \mathrm{CFI}=$ Difference in CFI values between models (where applicable);

Table 7: Path analysis of the research model.

\begin{tabular}{|c|c|c|}
\hline Direct Effect (Hypothesis) & SPC $^{1}$ & Outcome \\
\hline EOU->PE $\left(\mathrm{H}_{1}\right)$ & $.335 * * *$ & Accept \\
\hline REW->PE($\left(\mathrm{H}_{2}\right)$ & $.619 * * *$ & Accept \\
\hline
\end{tabular}

Table 8: Relationship between learners' perceived learning and actual learning performance

\begin{tabular}{lcc}
\hline Variable & $\mathbf{1}$ & $\mathbf{2}$ \\
\hline $\mathbf{1 . P E}$ & - & $.389^{*}$ \\
\hline 2.FS & $.389^{*}$ & -
\end{tabular}

$\mathrm{PE}=$ perceived learning through a serious game; $\mathrm{FS}=$ final scores of players in the game; $*(\mathrm{p}<0.05)$; 
Table 9: Subgroup analysis of the research model based on moderators

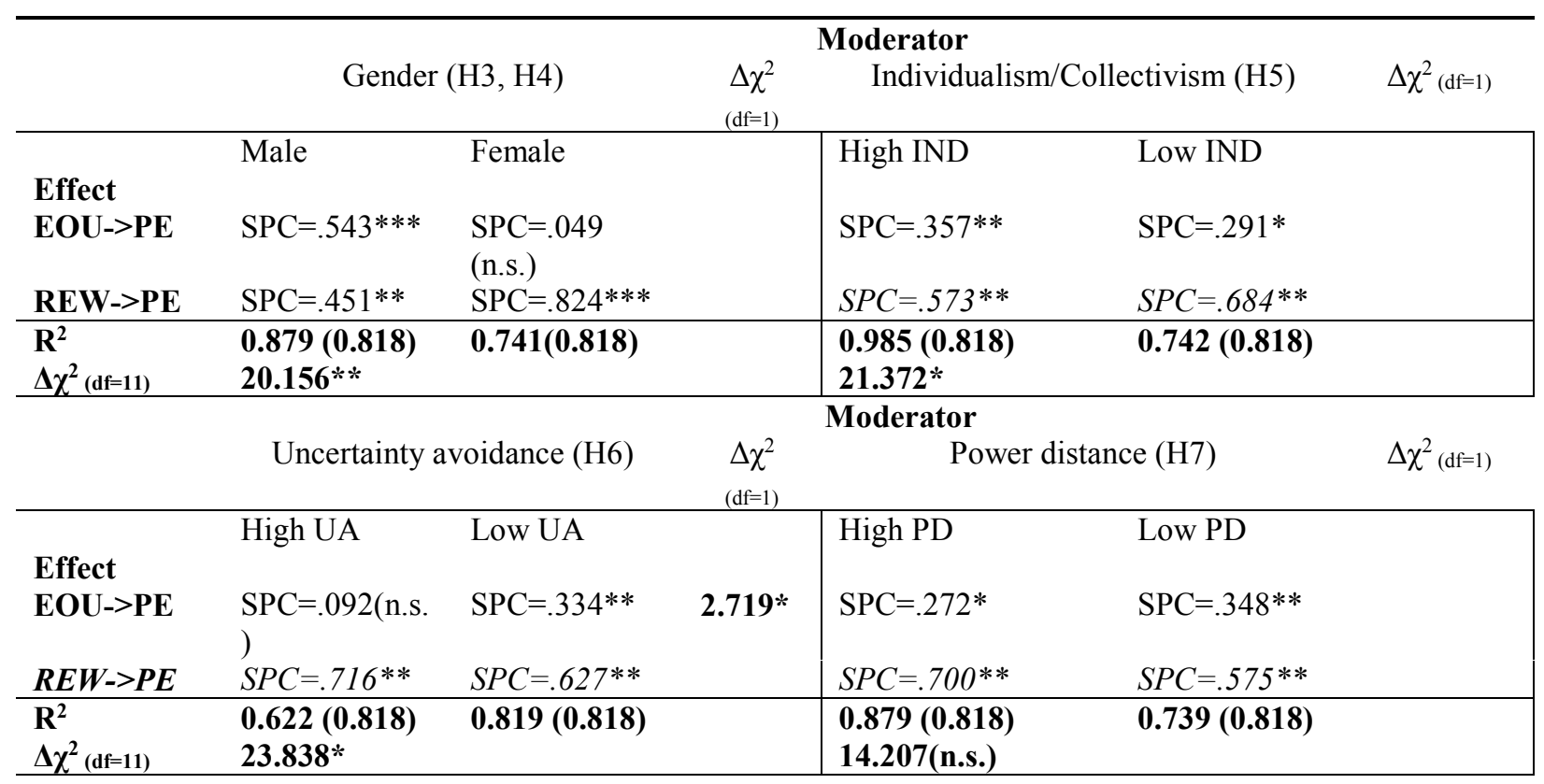

Note: values in brackets represent the $\mathrm{R}^{2}$ of the baseline model; $\Delta \chi^{2}{ }_{(\mathrm{df}=11)}$ is the chi-difference between the two groups after constraining the structural weight parameters; $\Delta \chi^{2}$ (df=1) is the chi-difference between the two groups based on constraining a parameter of interest which represents a hypothesised effect; SPC=standardised path coefficient uses for testing a hypothesis and SPC in italics indicates the standardised path coefficient values that is not part of any hypotheses that we posited but is nevertheless provided for additional insight; ${ }^{* * *}(\mathrm{p}<0.001) ;{ }^{* *}(\mathrm{p}<0.01) ;{ }^{*}(\mathrm{p}<0.05)$; n.s. (not significant) 
Table 10: Cross tabulation of gender against gaming experience

Game experience

\begin{tabular}{|c|c|c|c|c|}
\hline Gender & \multirow{3}{*}{$\begin{array}{l}\text { female } \\
\text { male }\end{array}$} & \multicolumn{2}{|c|}{ Low } & High \\
\hline \multirow[t]{2}{*}{ Gender } & & Cour & $128(87.1 \%)$ & $19(12.9 \%)$ \\
\hline & & $\mathrm{Co}$ & $70(56.9 \%)$ & $53(43.1 \%)$ \\
\hline & & $198(73.3 \%)$ & $72(26.7 \%$ \\
\hline
\end{tabular}


Figure 1: Hypothesised model for this research study (including moderators)

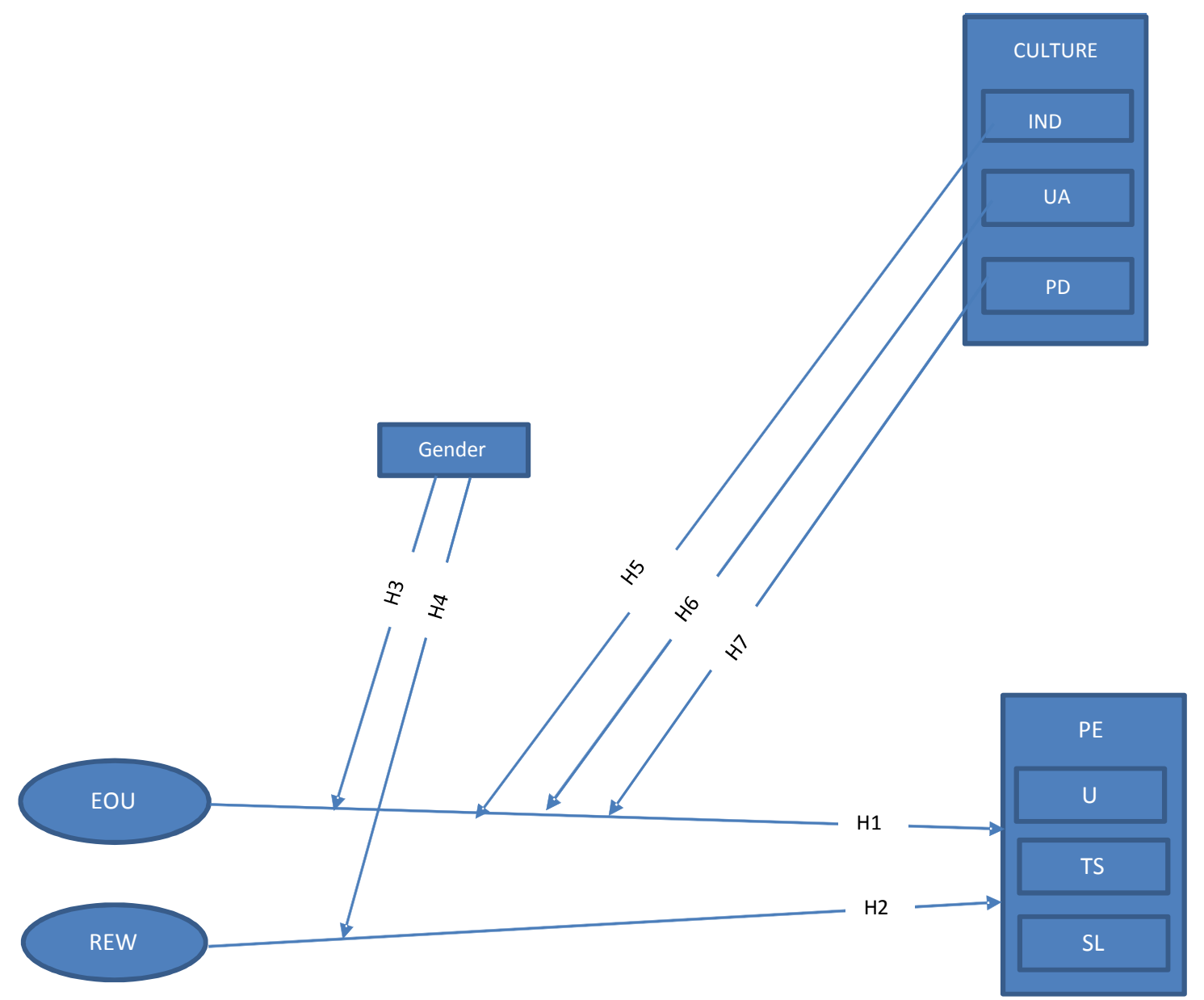

Note: $P E=$ perceived enjoyment, $E O U=$ perceived ease of use, $R E W=$ rewards, $P E=$ perceived effectiveness of a serious game as a practice-based managerial learning tool; $\mathrm{U}=$ perceived usability; $\mathrm{TS}=$ transferability of skills; $\mathrm{SL}=$ situated learning; $\mathrm{IND}=$ individualism index; $\mathrm{UA}=$ uncertainty avoidance index; $\mathrm{PD}=$ power distance index; 
Figure 2: An example of a full interaction and a decision completing with a reflection

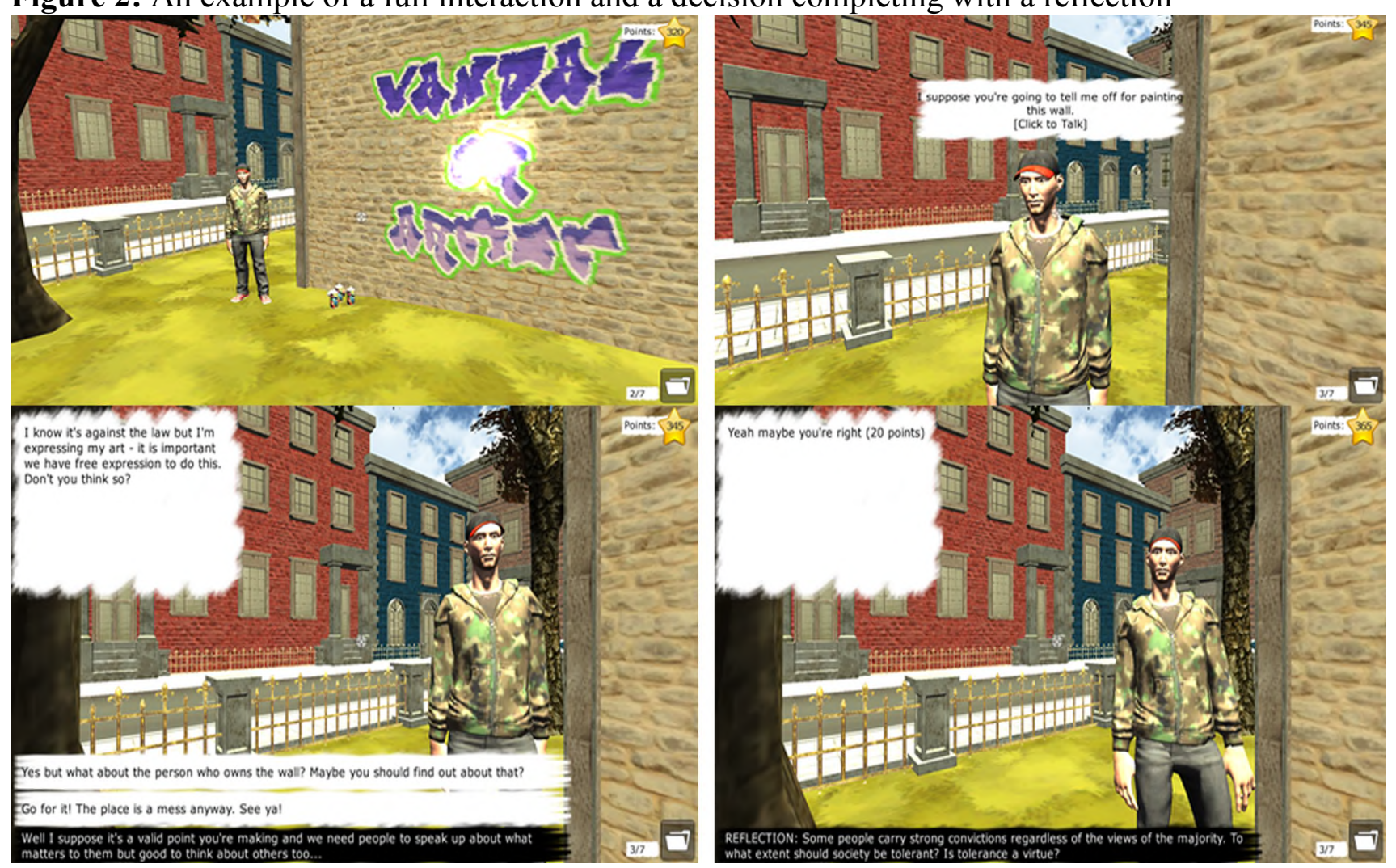


Figure 3: Results for research model (including moderators)

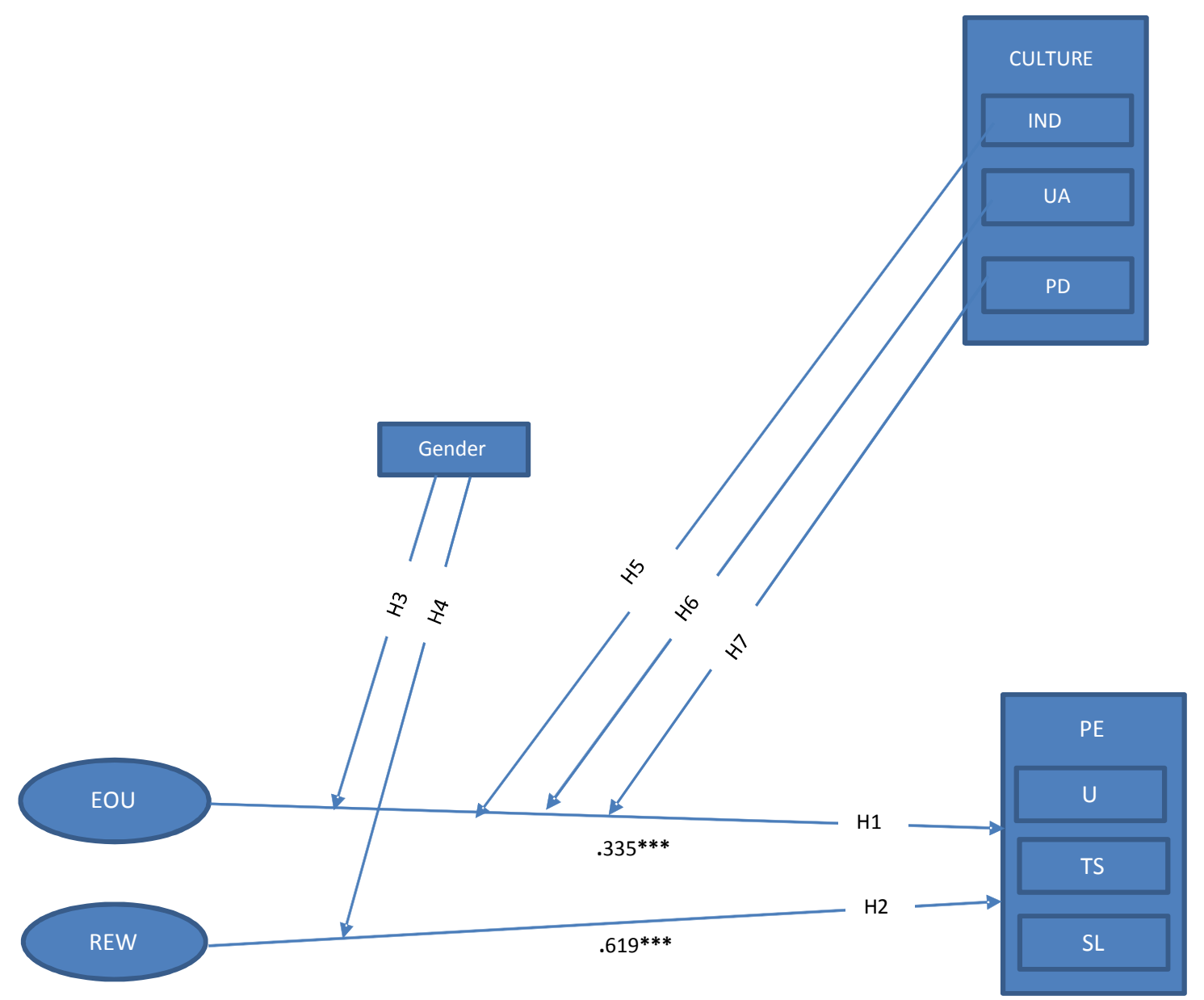

Note: $P E=$ perceived enjoyment, $E O U=$ perceived ease of use, REW=rewards, $P E=$ perceived effectiveness of a serious game as a practice-based managerial learning tool; $\mathrm{U}=$ perceived usability; $\mathrm{TS}=$ transferability of skills; $\mathrm{SL}=$ situated learning; $\mathrm{IND}=$ individualism index; $\mathrm{UA}=$ uncertainty avoidance index; $\mathrm{PD}=$ power distance index; $* * *(\mathrm{p}<0.001)$ 
Figure 4: Chart illustrating cultural group scores for the effect of the predictors perceived ease of use (EOU) and rewards (REW) on the criterion perceived effectiveness of serious games as a practice-based managerial learning tool (PE)

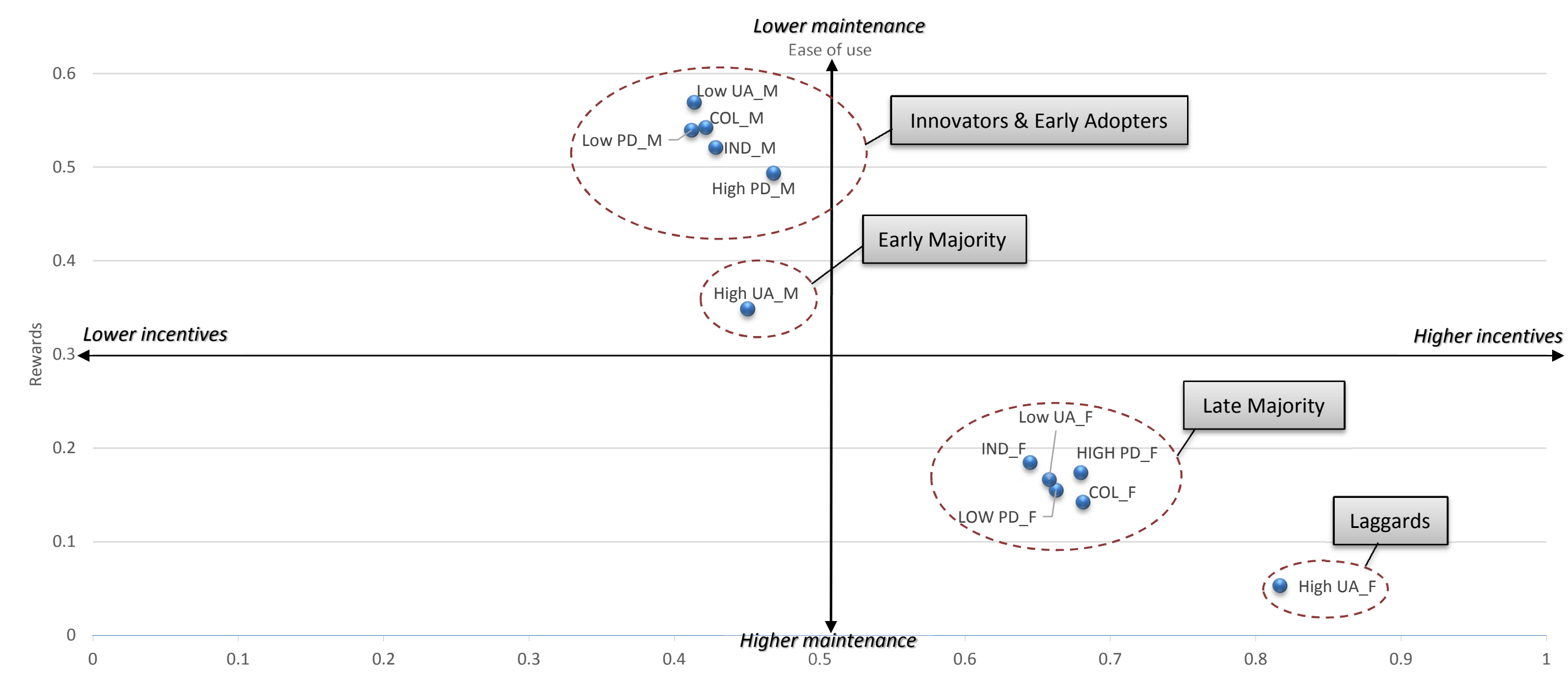

Note: $\mathrm{PD}=$ Power Distance; $\mathrm{UA}=$ Uncertainty Avoidance; $\mathrm{IND}=$ Individualism; $\mathrm{COL}=$ Collectivism; the affix _M and_F represent males and females in each cultural group, respectively; 


\section{Appendix 1}

Table A1: Measurement constructs and items used to test research model.

\begin{tabular}{|c|c|c|c|c|}
\hline Construct & Description & Item label & Measurement & Source \\
\hline REW & $\begin{array}{l}\text { The feedback } \\
\text { arrangement and } \\
\text { points awarded in the } \\
\text { game to motivate } \\
\text { participants to } \\
\text { complete the game. }\end{array}$ & $\begin{array}{l}\text { R1 } \\
\text { R2 } \\
\text { R3 } \\
\text { R4 }\end{array}$ & $\begin{array}{l}\text { I felt rewarded when I got points } \\
\text { I felt encouraged to learn more when I completed levels } \\
\text { Gaining points motivates me to keep on playing } \\
\text { I found that the points system was important to my learning }\end{array}$ & (Yusoff et al. 2010) \\
\hline EOU & $\begin{array}{l}\text { Ease-of-use is where } \\
\text { participants feel that } \\
\text { minimal effort is } \\
\text { required to learn how } \\
\text { to play the 3D game. }\end{array}$ & $\begin{array}{l}\text { EOU1 } \\
\text { EOU2 } \\
\text { EOU3 } \\
\text { EOU4 } \\
\text { EOU5 } \\
\text { EOU6 } \\
\text { EOU7 }\end{array}$ & $\begin{array}{l}\text { To use this game I would need expert help } \\
\text { Learning how to play this game is easy for me } \\
\text { It is easy to do what I want to do in the game } \\
\text { The game was flexible to interact with in most types of play } \\
\text { I find this game easy to use } \\
\text { Interacting with the game is clear and understandable } \\
\text { I could quickly become skillful at the game }\end{array}$ & $\begin{array}{l}\text { (Davis et al. 1989, Kim and Malhotra 2005, Shen } \\
\text { and Chu 2014, Wang, and Tseng 2014) }\end{array}$ \\
\hline $\mathbf{P E}$ & $\begin{array}{l}\text { Perceived } \\
\text { practicability of skills } \\
\text { and knowledge. A } \\
\text { self-reported } \\
\text { reflective measure of } \\
\text { the extent to which a } \\
\text { learner perceives the } \\
\text { serious game to be } \\
\text { effective for } \\
\text { acquiring ethical } \\
\text { skills and knowledge } \\
\text { that can be applied } \\
\text { and related to real- } \\
\text { life situations. Since } \\
\text { this is an adapted } \\
\text { version of the } \\
\text { original which } \\
\text { combines the items of } \\
\text { SL, we have } \\
\text { redefined this } \\
\text { construct as } \\
\text { "perceived } \\
\text { effectiveness of a } \\
\text { serious game as a } \\
\text { practice-based } \\
\text { managerial learning } \\
\text { tool" }\end{array}$ & $\begin{array}{l}\text { U2 } \\
\text { U3 } \\
\text { U4 } \\
\text { U5 } \\
\text { U6 } \\
\text { TS1 } \\
\text { TS2 } \\
\text { TS3 } \\
\text { TS4 } \\
\text { SL1 } \\
\text { SL2 } \\
\text { SL3 } \\
\text { SL4 }\end{array}$ & $\begin{array}{l}\text { The game will make ethical decisions easier in the future } \\
\text { I find the game useful to practice ethical decisions } \\
\text { The game will make me more efficient at making ethical decisions } \\
\text { Using this game helps me to make an ethical decision more quickly The game will improve my } \\
\text { performance when making ethical decisions } \\
\text { It was easier to retain knowledge learned in this game than in a textbook or lecture } \\
\text { The game helped me appreciate the skills needed in ethical decision making } \\
\text { From the game I have learned ethical decision making skills which can apply in different situations } \\
\text { From the game I have acquired new knowledge useful in day to day business decisions } \\
\text { The game motivates me because it deals with real issues } \\
\text { The issues presented in this game helped me to see from others' perspectives rather than just my } \\
\text { own } \\
\text { The game is close enough to real life to be useful to me } \\
\text { I feel that I can make an appropriate ethical decision in the workplace after playing this game }\end{array}$ & (Jagger et al 2015) \\
\hline
\end{tabular}




\section{Appendix 2}

Figure A1: An illustrative scene of an ethical dilemma

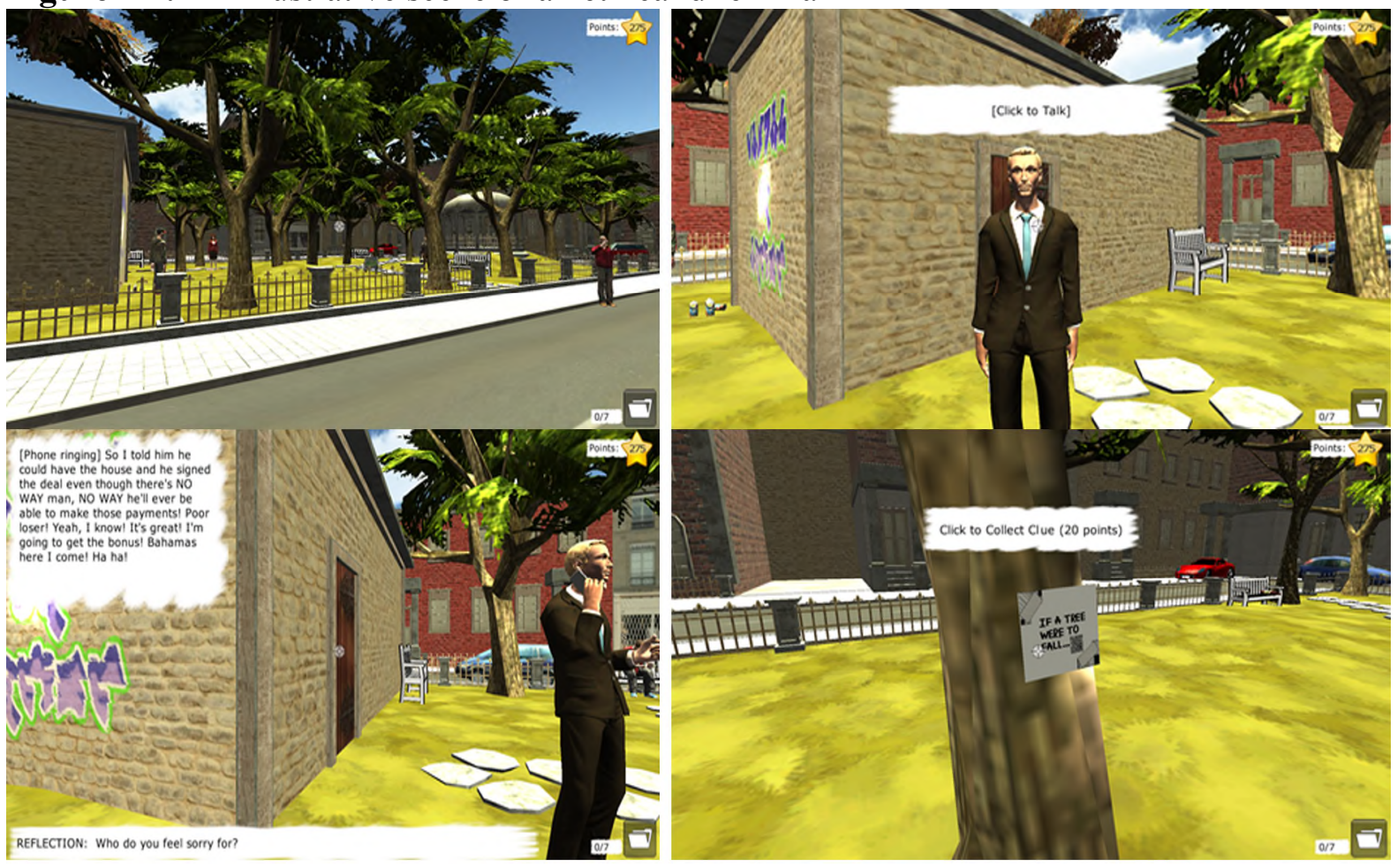

Figure A2: Accessing clues from the clue repository

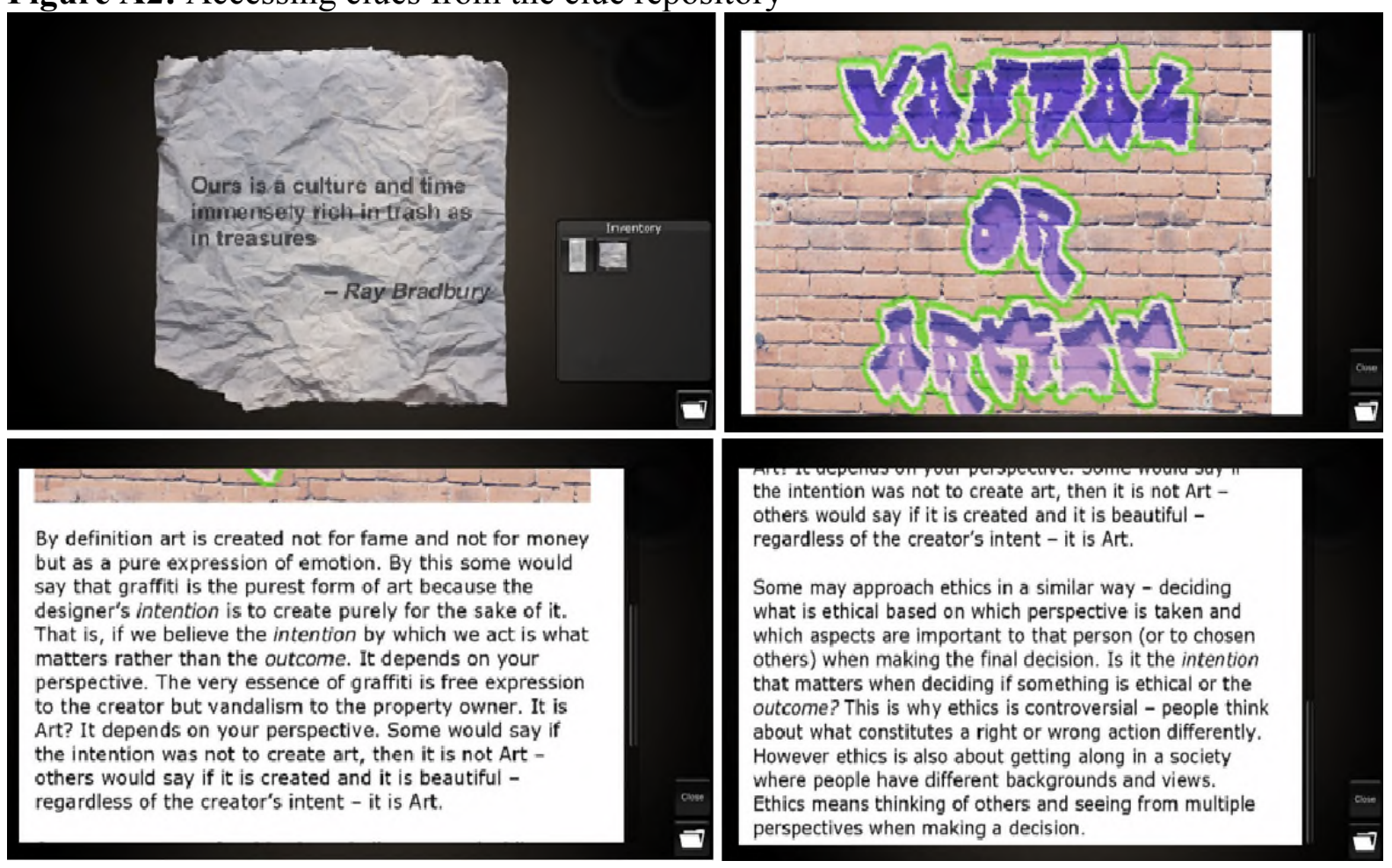




\section{Appendix 3}

Table A1: Item Discrimination Analysis: Results of Item Discriminatory Index

\begin{tabular}{cccc}
\hline \multicolumn{4}{c}{ Test Item Analysis } \\
\hline EOU2 & $D_{c}$ (individualism) & $D_{c}$ (uncertainty avoidance) & $D_{c \text { (power distance) }}$ 0.77 \\
PU1 & 0.84 & 0.71 & 0.69 \\
PU2 & 0.79 & 0.82 & 0.85 \\
EOU3 & 0.62 & 0.79 & 0.80 \\
PU3 & 0.77 & 0.63 & 0.62 \\
PU4 & 0.79 & 0.83 & 0.79 \\
EOU4 & 0.76 & 0.82 & 0.82 \\
EOU5 & 0.80 & 0.68 & 0.69 \\
PU5 & 0.78 & 0.78 & 0.76 \\
PU6 & 0.86 & 0.81 & 0.78 \\
EOU6 & 0.79 & 0.85 & 0.84 \\
EOU7 & 0.72 & 0.76 & 0.75 \\
TS1 & 0.72 & 0.68 & 0.68 \\
TS2 & 0.80 & 0.73 & 0.69 \\
TS3 & 0.80 & 0.82 & 0.80 \\
TS4 & 0.79 & 0.82 & 0.76 \\
R1 & 0.80 & 0.77 & 0.76 \\
R2 & 0.74 & 0.79 & 0.79 \\
R3 & 0.78 & 0.76 & 0.67 \\
R4 & 0.63 & 0.76 & 0.73 \\
SL1 & 0.76 & 0.69 & 0.64 \\
SL2 & 0.82 & 0.79 & 0.80 \\
SL3 & 0.74 & 0.77 & 0.79 \\
SL4 & 0.75 & 0.74 & 0.76 \\
\hline$D_{c}=$ Discrimination Index for upper and lower groups by cultural dimension
\end{tabular}

